
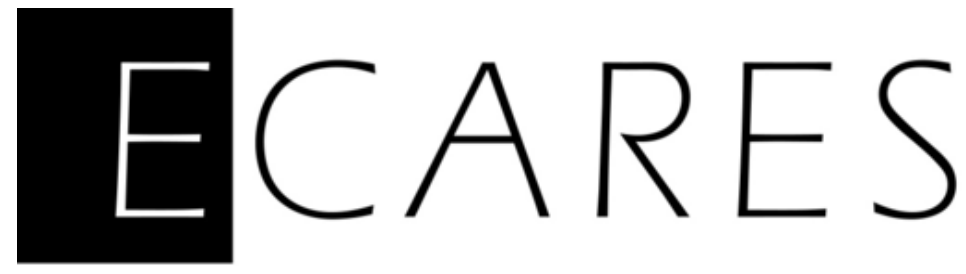

\title{
How Effective has the Electricity Social Rate been in Reducing Energy Poverty in Spain?
}

\section{Lisa Bagnoli}

ECARES, SBS-EM, Université libre de Bruxelles

F.R.S.-FNRS Aspirant

Salvador Bertomeu Sanchez

ECARES, SBS-EM, Université libre de Bruxelles

Compass Lexecon, Belgium

February 2021

ECARES working paper 2021-05

ECARES

ULB - CP 114/04

50, F.D. Roosevelt Ave., B-1050 Brussels BELGIUM

www.ecares.org 


\title{
How effective has the electricity social rate been in reducing energy poverty in Spain? *
}

\author{
Lisa Bagnoli ${ }^{1,2}$ and Salvador Bertoméu-Sánchez ${ }^{1,3}$ \\ ${ }^{1}$ Université libre de Bruxelles (ECARES) \\ ${ }^{2}$ F.R.S.-FNRS Aspirant \\ ${ }^{3}$ Compass Lexecon, Belgium
}

\begin{abstract}
This paper analyzes the effectiveness of the electricity social rate, the Bono Social de Electricidad, introduced in 2009 in Spain's electricity market. It is a policy aimed at increasing the affordability of electricity by entailing a discount on prices for vulnerable consumers. Using data from the family budget survey from 2006 to 2017, we rely on a difference-in-differences approach to measure its causal impact on energy poverty and to further analyze how the introduction of this measure affected the consumption behavior of households. We find that, on average, the introduction of the policy has reduced the likelihood of energy poverty of households eligible to the social rate. Nevertheless, the magnitude of the effect is quite modest as it corresponds in practice to only 59,000 households that are no longer in energy poverty as a result of the measure. We further show that, in reaction to lower effective prices, households do not increase their consumption of electricity. In other words, the increased affordability did not induce a change in the consumption behavior in terms of quantities purchased but it entirely resulted in a decrease in electricity expenditure.
\end{abstract}

Keywords: Electricity, energy poverty, policy evaluation, social rate.

JEL classification: Q48, Q41, I38, D12, C1.

\footnotetext{
*lisa.bagnoli@ulb.be. 50, Av. F.D. Roosevelt, CP 139, B-1050 Brussels, Belgium. We are grateful for discussions, comments, and suggestions to G. Aldashev, G. Bel, B. De Rock, A. Estache, P. Gobbi, M. Parenti, and T. Serebrisky.
} 


\section{Introduction}

Traditionally, energy poverty, i.e. the inability to ensure the provision of basic energy services at an affordable cost, was considered to be a concern related almost exclusively to developing countries. However, during the last decade, the issue has also made it to the policy agenda in developed economies. In the European Union for instance, 50 million households are in a situation of energy poverty, ${ }^{1}$ with important negative social and economic consequences (see for instance Awaworyi Churchill et al. (2020)). While this situation is widespread throughout Europe, its geographical distribution is quite uneven, the issue particularly afflicting Southern and Eastern Member States (Tirado Herrero et al., 2014). Spain has not been spared by this phenomenon.

Indeed, the severity of the 2008 crisis has seemed to make the issue of energy poverty even more acute in Spain than in other European countries (Tirado Herrero and Jiménez Meneses, 2016; Haas, 2019). As a response, the Spanish government introduced in 2009 an electricity social rate: the Bono Social de Electricidad $(B S E) .{ }^{2}$ It is a policy entailing a discount on the electricity prices for vulnerable consumers. Its objective is to decrease energy poverty by increasing consumer's affordability.

The goal of this paper is twofold. First, we investigate the effectiveness of this instrument in tackling energy poverty. Second, we aim to understand how the measure affected directly households and their consumption behavior.

To be able to assess the effectiveness of the $B S E$ on energy poverty in Spain, we use data from the family budget survey from 2006 to 2017 . We rely on a standard differencein-differences approach to compare the evolution of energy poverty before and after the introduction of the BSE in 2009 for households that meet the criteria for BSE eligibility, relative to the evolution of energy poverty of the control group, i.e. households that are not eligible to the social rate. In a second step, we investigate the mechanisms through which this subsidy directly affected households. In particular, we apply the same differencein-differences model to three different dependent variables, namely the effective price of electricity, the quantities of electricity consumed and the total expenditure in electricity.

Our results show that the $B S E$ as introduced in 2009 was effective in reducing energy poverty among the eligible households. Nevertheless, they also show that the magnitude of the this effect is quite modest. Indeed, the $B S E$ significantly reduces the likelihood of energy poverty for an eligible household by 2 percentage points. It corresponds to only 59,000 households

\footnotetext{
${ }^{1}$ https://www . energypoverty.eu/about/what-energy-poverty.

${ }^{2}$ This measure specifically focuses on electricity and not energy as a whole. Therefore, throughout the paper we focus on energy poverty related only to electricity but we refer to it as energy poverty to remain consistent with the literature. Moreover, as shown by Tirado Herrero and Jiménez Meneses (2016), among domestic energy costs, the rise in electricity expenditure is the most significant increase after 2008 in Spain.
} 
that are no longer in energy poverty as a result of the introduction of the BSE. The second part of the analysis confirms that the $B S E$ decreases the effective price of electricity faced users benefiting from the program. In response to this lower effective price, households do not increase the quantity of electricity purchased. As a result, the entire effect of the subsidy is channeled through a reduction in the expenditure in electricity. This increased affordability of electricity does therefore not imply a change of consumption behavior for electricity. We complement our analysis with a discussion from a policy perspective and we conclude that even though our main results are conservative and represent a lower bound for the true effect of the $B S E$, the policy cannot be described as successful in reducing energy poverty and could be improved on several dimensions.

Our results add to the recent literature on energy poverty. This literature has widely analyzed the main micro-level drivers of energy poverty. It has shown that socio-economic and dwelling characteristics are important predictors of energy poverty. For instance, Miniaci et al. (2014), Legendre and Ricci (2015), Scarpellini et al. (2015), and Robinson et al. (2018) all show for different European countries that income levels, living in rural areas, higher education or owning the dwelling decrease energy poverty. The same socio-economic and dwelling characteristics seem equally important to predict the share of expenditure in electricity (see Jimenez and Yepez-Garcia (2017), for Latin American countries and Besagni and Borgarello (2018), for Italy).

In Spain, though energy poverty has worsened between 2005 and 2016 (Aristondo and Onaindia, 2018), there exists very little evidence analyzing its main determinants (CostaCampi et al., 2019). Among the few, Lasarte Navamuel et al. (2018) identify detached houses, owning them and a higher number of household members as factors increasing the odds of energy poverty, while living in an urban agglomeration decreases them with respect to living in rural areas. Tirado Herrero et al. (2018) argue that education, employment, the type of employment, the marital status, having household members affected by illness or receiving social subsidies are all key factors in determining whether a household is in a situation of energy poverty. All these papers highlight variables that have to be considered in our analysis.

From an institutional perspective, the literature has analyzed considerably the effects of institutional reforms such as privatization or the introduction of regulation in the electricity sector (see for instance Balza et al. (2013), or Bagnoli et al. (2020) for a review), but has looked very little into the role they have played in the growing issue of energy poverty, both in Europe and at a global scale. ${ }^{3}$ The closest study to energy poverty is the one by Poggi and Florio (2010), which shows that privatizations increase the likelihood of deprivation, defined as the difficulty in paying bills.

\footnotetext{
${ }^{3}$ See the EU Energy Poverty Observatory http://energypoverty.eu
} 
In Spain, the only paper that has, to our knowledge, focused on the impact of the $B S E$ on energy poverty is García Alvarez and Tol (2020). Contrary to the approach we take, they use self-reported indicators, such as the ability to keep the house adequately warm, or whether there are isolation or moisture related problems in the dwelling. They find that the introduction of the BSE had no significant impact on these indicators, and if anything, it has made the problem worse. Therefore, the main difference in our approach is that we focus on an objective measure of energy poverty. Moreover, by investigating the mechanism of consumption behavior, we add that consumers do not change the quantities of electricity purchased.

In sum, our contribution is threefold. First, we add to the scarce literature on the effectiveness of specific policy instruments tackling energy poverty. In particular, we look at a specific instrument that targets prices independently of the quantity of electricity consumed. Second, we provide evidence on household behavioral response following the introduction of a social rate. We do so by investigating in detail the effect of this policy on quantities of electricity purchased and the resulting expenditure in electricity. Third, we contribute to the large debate on energy poverty in Spain and its determinants across both socioeconomic and institutional characteristics.

The remainder of the paper is structured as follows. Section 2 reviews the definition and different measurements of energy poverty, and the provides context on the Spanish case and the specific characteristics of the BSE. In section 3 and section 4, respectively, we review the data and the empirical strategy used in the analysis. Section 5 presents the results, first focusing on the effect of the BSE on energy poverty, and then on the mechanisms behind such an effect. We present the robustness checks in section 6 . Finally, section 7 evaluates the $B S E$ from a policy perspective while section 8 concludes.

\section{Background}

In this section, we first review review the concept of energy poverty and its indicators. We then describe the energy poverty background in Spain and give details on the introduction of the $B S E$.

\section{$2.1 \quad$ Energy poverty}

This subsection focuses on the definition of energy poverty, the different types of indicators used to measure it, and the reasons behind the choices made in this analysis. 


\subsubsection{Definition of the concept}

Energy poverty is often defined as a situation in which households are not able to adequately heat or provide required energy services in their homes at an affordable cost (Pye et al., 2015). While in developing countries much of the focus is on access and availability of modern energy services (Okushima, 2017), developed countries mainly focus on the affordability of energy. This multidimensional concept covers the interaction between five components: (i) energy costs, (ii) income, (iii) energy efficiency, (iv) individual energy needs and (v) climatic conditions (Healy and Clinch, 2002; Phimister et al., 2015; Okushima, 2017). As such, even though the concepts of energy poverty and income poverty are related, the first is not a mere symptom of the second since many other components are involved. Several empirical studies have confirmed that these are two severe and distinct issues (see for instance Hills (2012) or Phimister et al. (2015)).

\subsubsection{Indicators and measures}

Given the multidimensional nature of energy poverty, there is an important debate in the literature on the choice of an appropriate indicator, which is however key in deciding how to deal with it (Heindl and Schüssler, 2015; Thomson et al., 2016; Deller, 2018). The literature distinguishes between two main types of indicators: the consensual indicators, based on self-reported measure of energy poverty and expenditure-based indicators, capturing the affordability of energy services using information on the household's spending (see for instance Castaño-Rosa et al. (2019), Thomson et al. (2016), or Rademaekers et al. (2016) for detailed reviews of the different definitions of energy poverty).

In our analysis, there are four reasons to prefer expenditure-based indicators. First, according to Rademaekers et al. (2016), expenditure-based indicators are currently the most appropriate measures of energy poverty in the European context. Second, the majority of the research on energy poverty relies on subjective indicators. Though subjective indicators do allow to describe and highlight this issue, objective indicators are needed in order to conduct more precise quantitative assessments and inform on the necessary policies to tackle the problem (Rademaekers et al., 2016). Third, the use of budgetary information allows to disentangle whether the effect of a policy on energy poverty comes through prices or quantities consumed. And finally, in the context of the Spanish BSE, a social rate for electricity, expenditure-based indicators allow to specifically look at electricity expenditure, instead of all energy sources, which is not feasible when using consensual measures.

Among expenditure-based indicators, we rely on the EP-2M indicator defined as follows:

A household is in energy poverty if its share of expenditure in electricity is more than twice the median of the country. 
This indicator allows to identify households allocating an unusually high share of expenditure to electricity, therefore detecting households who compromise on the consumption of other goods because of energy costs. This indicator is widely recommended (see Rademaekers et al. (2016)) and it is one of the primary indicators used by both the recently created European Energy Poverty Observatory and the Spanish National Strategy against Energy Poverty 2019-2024 (Ministerio para la Transición Ecológica, 2019). Moreover, by using a threshold defined by the median of the distribution, we avoid making an arbitrary decision on which share of electricity expenditure would be considered as too high. We ensure in section 6 that our results are robust to alternative definitions of the energy poverty indicator.

\section{$2.2 \quad$ Energy poverty in Spain}

Energy poverty has become a growing issue in Spain, particularly since the beginning of the financial crisis in 2008. Figure 1 shows the evolution of the share of households in a situation of energy poverty, as measured by the indicator used in the empirical analysis (EP-2M). The figure shows that the share of households in energy poverty increased from around $12.5 \%$ to $15 \%$ from 2007 to 2009 . It then decreased steadily until reaching $12 \%$ in 2014, level at which it has remained quite stable until 2017.

Figure 1 also shows that the decrease in the share of households in a situation of energy poverty started in 2009, coinciding with the introduction of the BSE. It is, however, impossible to graphically determine whether such a decrease was the result of the implementation of the measure, or whether it was related to other factors, such as an attenuation in the effects of the crisis. This is what we address in our econometric analysis.

Since the measure of energy poverty is based on the share of expenditure allocated to electricity, it is relevant to understand how much do households spend on electricity and what share of their total expenditure this represents. Figure 2 illustrates these two variables for the different quintiles of the total expenditure distribution. It shows that, across quintiles, although total expenditure is increasing, the share of expenditure allocated to electricity is decreasing with income levels. The richest quintile of the population spends on average less than $2 \%$ of its expenditure on electricity, while this is more than doubled for the poorest quintile of the population. This heterogeneity across quintiles sheds light on why the EP-2M indicator is based on the share of expenditure in electricity rather than on total expenditure in electricity.

Besides the heterogeneity across quintiles, there exists a spatial heterogeneity in the share of energy poverty across Spain. Figure 3 shows the regional differences in the average share of households in a situation of energy poverty by region over the years 2006 to 2017. Regions in the southern half of the country, namely Andalucía, Balearic Islands, Castilla La Mancha, 


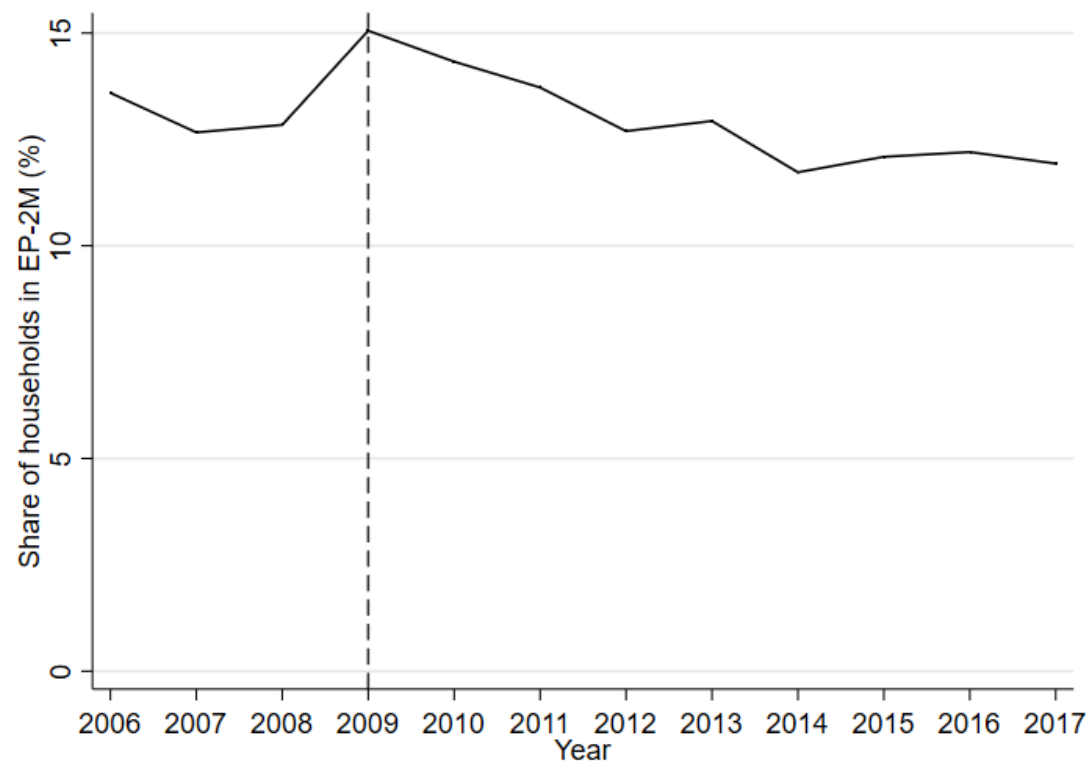

Notes: The vertical dashed line in 2009 represents the year of introduction of the BSE.

Source: EPF 2006-2017

Figure 1: Evolution of the share of households in energy poverty in Spain

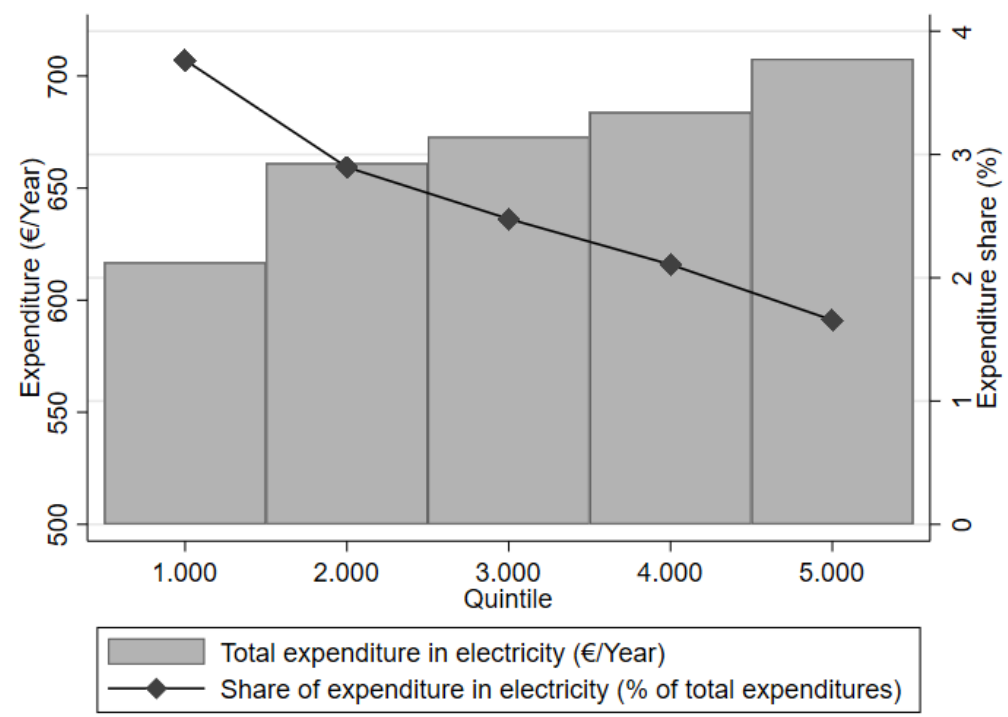

Notes: Averages over the period 2006-2017. Quintiles are based on the per capita expenditure distribution. Expenditure is indexed on IPC (base 2016).

Source: EPF 2006-2017

Figure 2: Total expenditure in electricity and share of electricity expenditure, by quintiles 
Comunidad Valenciana, Extremadura and Murcia are particularly affected, especially when compared with the northern regions. While the average ranges from $5 \%$ to $14 \%$ of energy poverty in northern regions, it climbs to $15 \%$ to $22 \%$ in southern ones. There is therefore a regional pattern in the distribution of energy poverty in Spain.

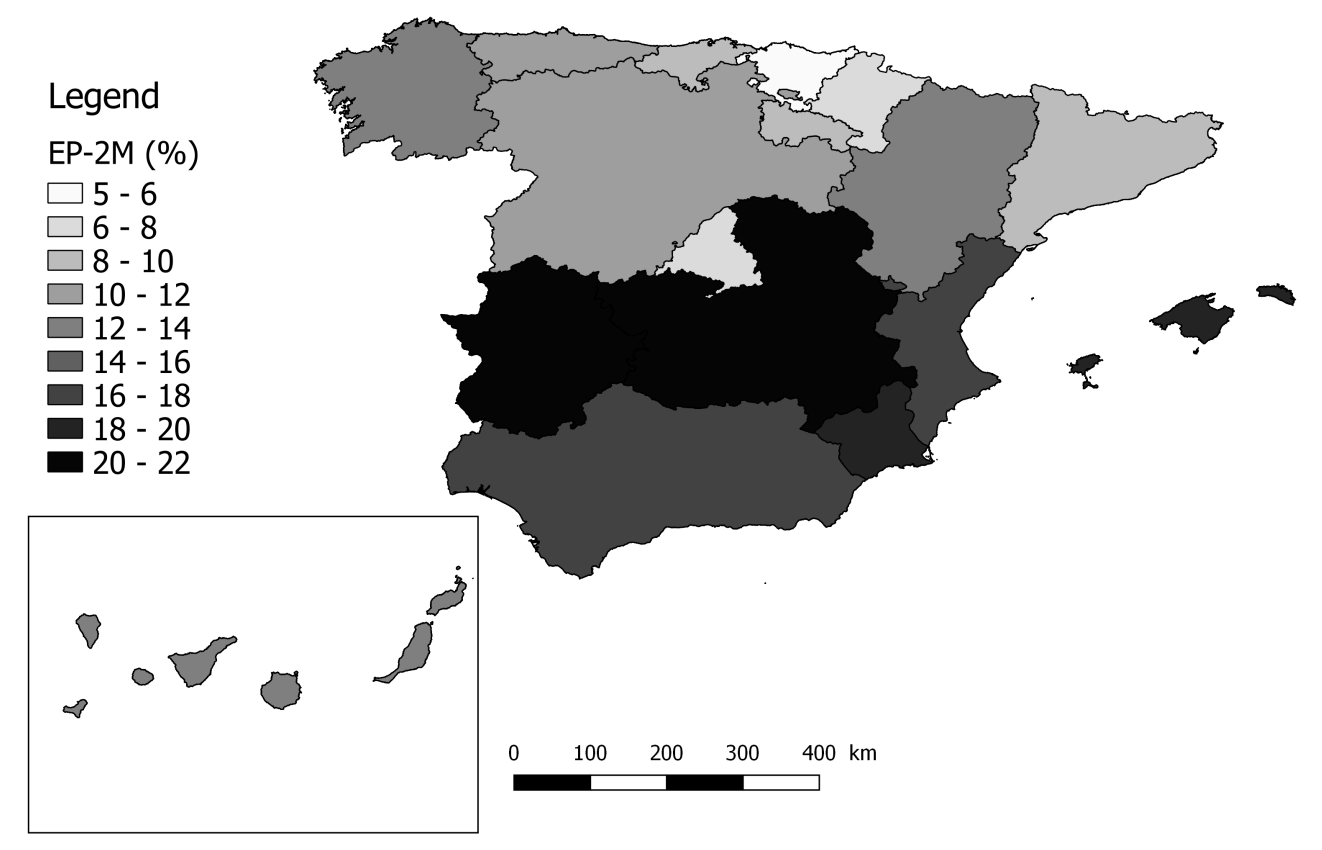

Note: Average share of households in EP-2M over 2006-2017.

Source: EPF 2006-2017

Figure 3: Energy poverty in Spain: differences across regions

\subsection{The social electricity rate in Spain (BSE)}

To address the surging energy poverty, the Spanish government introduced the Bono Social de Electricidad (BSE) in 2009 through Royal Decree-Law 6/2009. ${ }^{4}$ It is an electricity social rate introduced as a response to pressure from various sources, including the public opinion and media, as well as supranational organizations. Indeed, the European Union also urged Spain to tackle the energy poverty (Tirado Herrero et al., 2014). The objective of this measure is to improve the affordability of electricity for vulnerable consumers, and it is the only measure at the national level that directly targets energy poverty.

In practice, the $B S E$ is a price subsidy that equals the difference between the regulated

\footnotetext{
${ }^{4}$ https://www.boe.es/eli/es/res/2009/06/26/(2)
} 
tariff, and a reference value known as the reduced tariff. ${ }^{5}$ The subsidy is advertised as being entirely financed by the private electricity operators, instead of with public funds. ${ }^{6}$ However, in practice, the burden is likely to be carried by both consumers and the government instead of the private companies. We will discuss this in more detail in section 7 .

This policy targets vulnerable consumers through the following rule. A household is eligible for the $B S E$ by meeting (at least) one of the following criteria:

(1) Large families with 3 dependent children or more;

(2) All active members of the household are unemployed;

(3) Retirees receiving the minimum pension;

(4) Consumers having contracted power in their homes lower than $3 \mathrm{~kW}$.

\section{Data and descriptive statistics}

This section describes the dataset and presents in detail each of the variables that are used in the analysis. It also provides descriptive statistics on the key variables.

\subsection{Data}

The empirical analysis in this paper relies on repeated cross-sections from the Spanish annual family budget survey (EPF), from 2006 to $2017 .{ }^{7}$ The survey collects detailed information on the expenditure of Spanish households, it also includes various household and dwelling characteristics. Initially, the data set contained 261,478 valid observations. Following the data cleaning process, the sample used in the analysis consists of between 246,928 and 246,744 observations, depending on the variable (see Appendix A for the details of the cleaning process).

\subsection{Energy poverty and other outcome variables}

The main outcome variable of the analysis is whether a household is in a situation of energy poverty, which we measure using the EP-2M indicator. Figure 4 presents the evolution of the threshold for energy poverty, i.e. twice the median of national expenditure share. It shows that the $2 \mathrm{M}$ threshold varies considerably over the period of study. It remained stable around 3\% during the first years of the period of study. In other words, the median household spent $1.5 \%$ of its expenditure on electricity. Then, between 2008 and 2012, and coinciding with the surge in energy poverty following the beginning of the great recession,

\footnotetext{
${ }^{5}$ The regulated tariff was known as Precio Voluntario al Pequeño Consumidor until 2013, and Tarifa de último recurso since then.

${ }^{6}$ https://www.cnmc.es/node/373177

${ }^{7}$ Encuesta de Prespupuesto Familiares, collected by the National Institute of Statistics (INE) https: //ine.es
} 


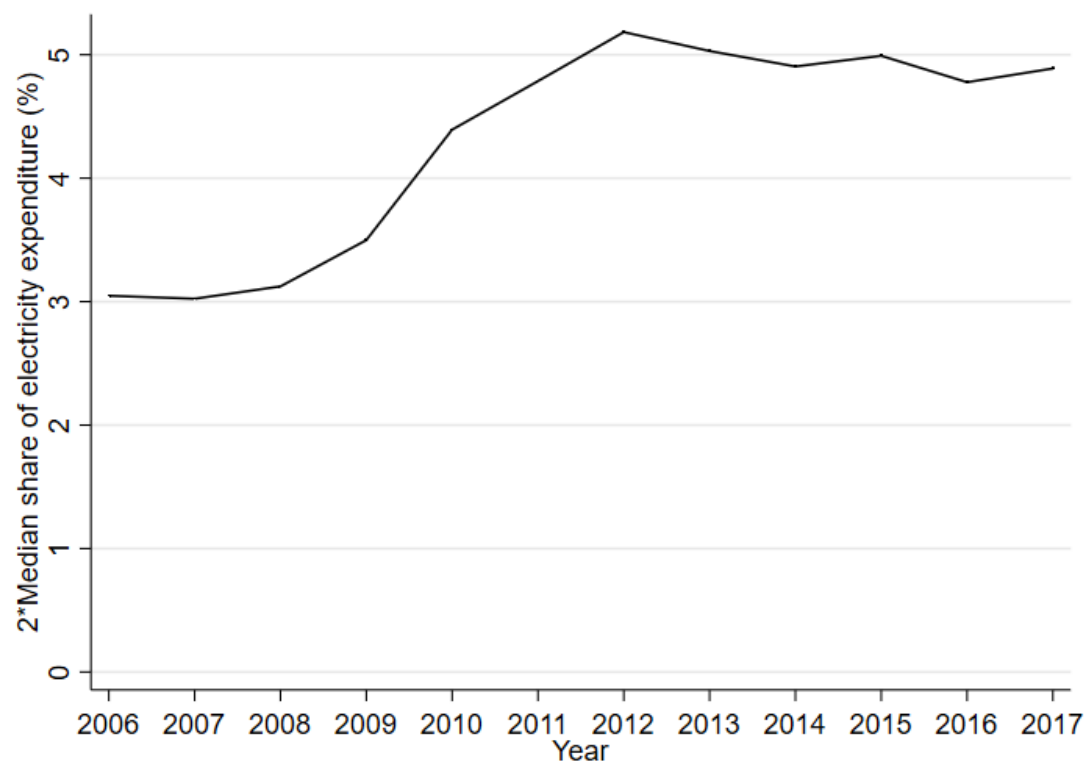

Source: EPF 2006-2017

Figure 4: Evolution of 2M threshold over time

the $2 \mathrm{M}$ threshold jumped to around $5 \%$, remaining stable until the end of the period of study.

Panel A of Table 1 presents the descriptive statistic for both the share of electricity expenditure and energy poverty. Over the period of study, Spanish households spend on average $2.6 \%$ of their expenditure on electricity, and $13 \%$ of them are in a situation of energy poverty.

Then, to understand the mechanisms of the policy, we introduce three additional outcome variables. Panel B of Table 1 presents their descriptive statistics. We first compute the effective price of electricity faced by households by dividing expenditures by quantities. This results in an average effective price of 0.214 euro per $\mathrm{kWh}^{8}$ We then look at the quantity of electricity consumed. On average households consume $3330 \mathrm{kWh}$ per year. Finally, we look at the expenditure in electricity. Households spend on average 668 euro per year.

\subsection{Treatment variable}

To be able to measure the causal impact of the introduction of the $B S E$ on energy poverty, the treatment and controls groups consist respectively of the households who are eligible to the subsidy and those who are not. Unfortunately, the dataset does not include whether

\footnotetext{
${ }^{8}$ Note that whenever we mention prices and expenditures, they have been converted in real terms using IPC in base 2016 .
} 


\begin{tabular}{|c|c|c|c|}
\hline & $\mathrm{N}$ & Mean & St. Dev. \\
\hline \multicolumn{4}{|l|}{ Panel A: } \\
\hline Share of electricity expenditure & 246,928 & 0.026 & 0.017 \\
\hline Energy poverty (EP-2M) & 246,928 & 0.130 & 0.336 \\
\hline \multicolumn{4}{|l|}{ Panel B: } \\
\hline Effective price of electricity $(€ / \mathrm{kWh})$ & 246,928 & 0.214 & 0.055 \\
\hline Quantity of electricity consumed (kWh/year) & 246,928 & 3329.74 & 2386.40 \\
\hline Expenditure in electricity (€/year) & 246,928 & 668.47 & 418.42 \\
\hline
\end{tabular}

Average over 2006-2017. Expenditures and effective prices are indexed using IPC base 2016. N: number of observations. St. Dev.: standard deviation.

Table 1: Summary statistics of household electricity consumption

the concerned households actually subscribed to the subsidy. As a result, our identification strategy consists of selecting those households in the survey that fill the criteria to receive the subsidy, in other words, those that are eligible to the $B S E$ in order to form the treatment group.

As explained in section 2.3, households are eligible for the $B S E$ if they fill (at least) one out of four criteria. These relate to large families, unemployment, pensions, and power contracted. The survey allows to perfectly identify households related to the first two categories, i.e. the large families and households where all active members are unemployed. The data also allow to create a proxy for the third criteria, i.e. retirees receiving the minimum pension (see Appendix B for a description of the construction of this proxy). The data does not however allow to proxy for the fourth criteria, the one related to the power contracted by the households. We therefore rely on the hypothesis that many households that are concerned with this criteria are anyhow identified through one of the three other criteria. ${ }^{9}$ This means that on average over the period of the analysis, $15.95 \%$ of households in the sample are eligible to the $B S E$.

Once we have identified eligible households, we can compare the share of households that are eligible to the $B S E$ according to our computations, and the share of households that actually received the BSE, i.e. the official beneficiaries as detailed by the regulator CNMC. Figure 5 shows the evolution of these two shares between 2006 and 2017. Note that as the $B S E$ was only introduced in 2009, there are no actual beneficiaries before that year. We can however identify households that fulfil the eligibility criteria even before 2009. The figure also shows that except for 2009 and 2010, the number of eligible beneficiaries, as identified

\footnotetext{
${ }^{9}$ This hypothesis induces a risk of spillover from the treatment to the control group, which reduces the observed difference between the treatment and control groups. The proxy for the minimum pension criteria might also induce spillovers between the two groups. Both of these effects however go in the same direction, that is that the treatment effect observed in the analysis is an under-estimation of the true effect.
} 
in the analysis, is above the official number of subscriptions. This is consistent with the fact that eligible households are by definition more numerous than those who actually subscribed to the $B S E .^{10}$

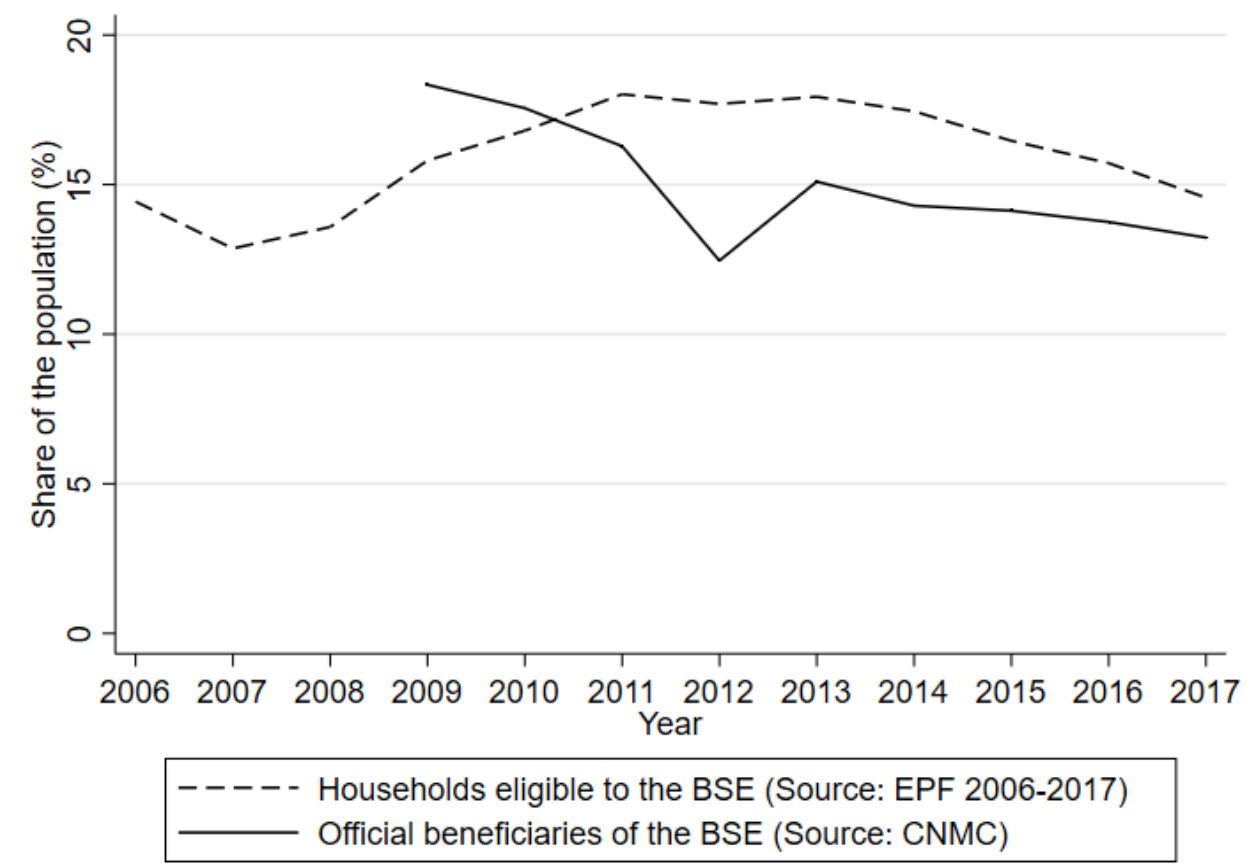

Figure 5: Households eligible to the BSE and official beneficiaries - 2006-2017

Figure 6 presents the share of households who are in energy poverty, before and after 2009 and by eligibility to the $B S E$. The figure shows that households who are eligible to the $B S E$ are also more likely to be in a situation of energy poverty. The gap however narrows after 2009. Indeed, in both time periods, there are around $11 \%$ of households who are not eligible to the $B S E$ who are in energy poverty. For eligible households, it goes from $26 \%$ to $22 \%$ on average.

Finally, as the $B S E$ induces a reduction in the effective price of electricity faced by households subscribing to the subsidy, Figure 7 shows the evolution of the effective price according to whether the household is eligible to the subsidy. It confirms that from 2009, the year of introduction of the $B S E$, the effective price between eligible households and non eligible ones starts diverging.

\footnotetext{
${ }^{10}$ This also reduces concerns that by not including the criteria about contracted power we could have excluded a large share of eligible households.
} 


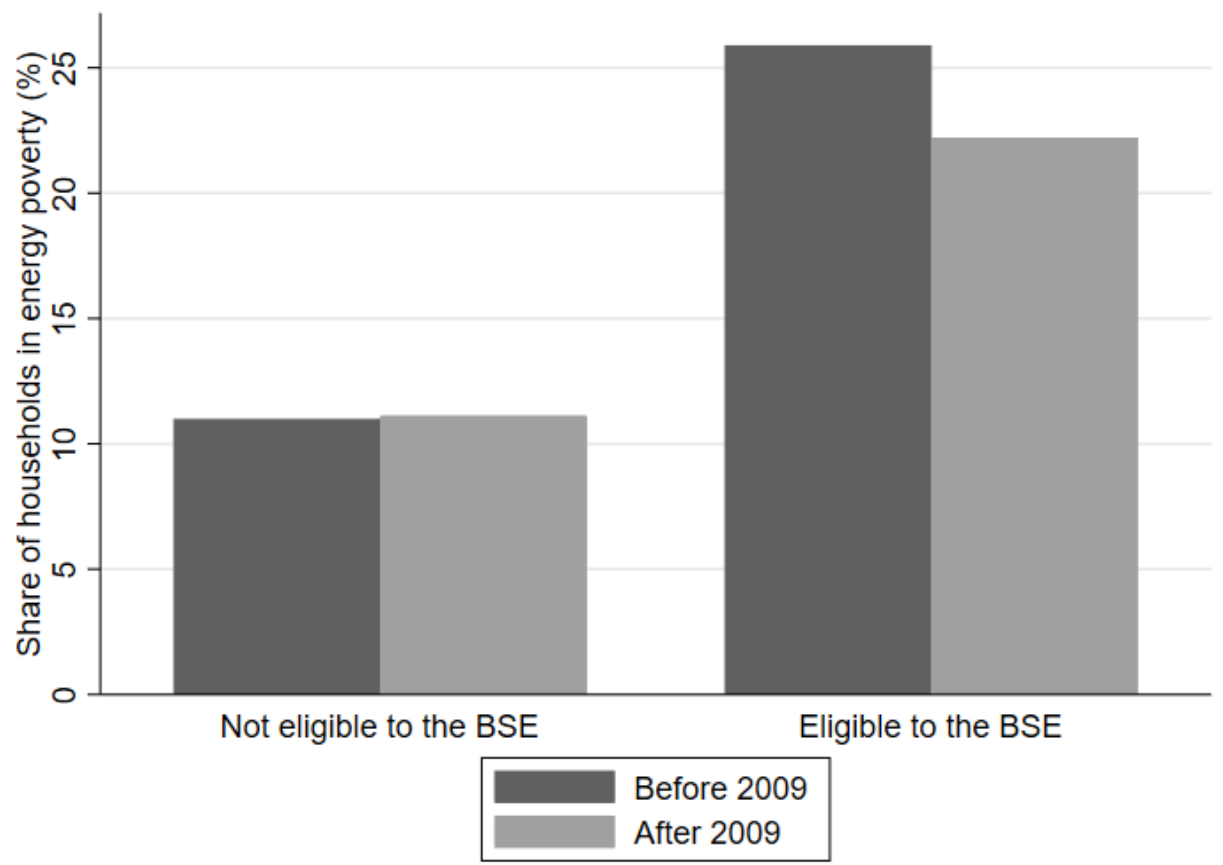

Note: Data from 2006 until 2017. The category “After 2009" includes the year 2009.

Figure 6: Energy poverty by eligibility to the $B S E$, before and after 2009

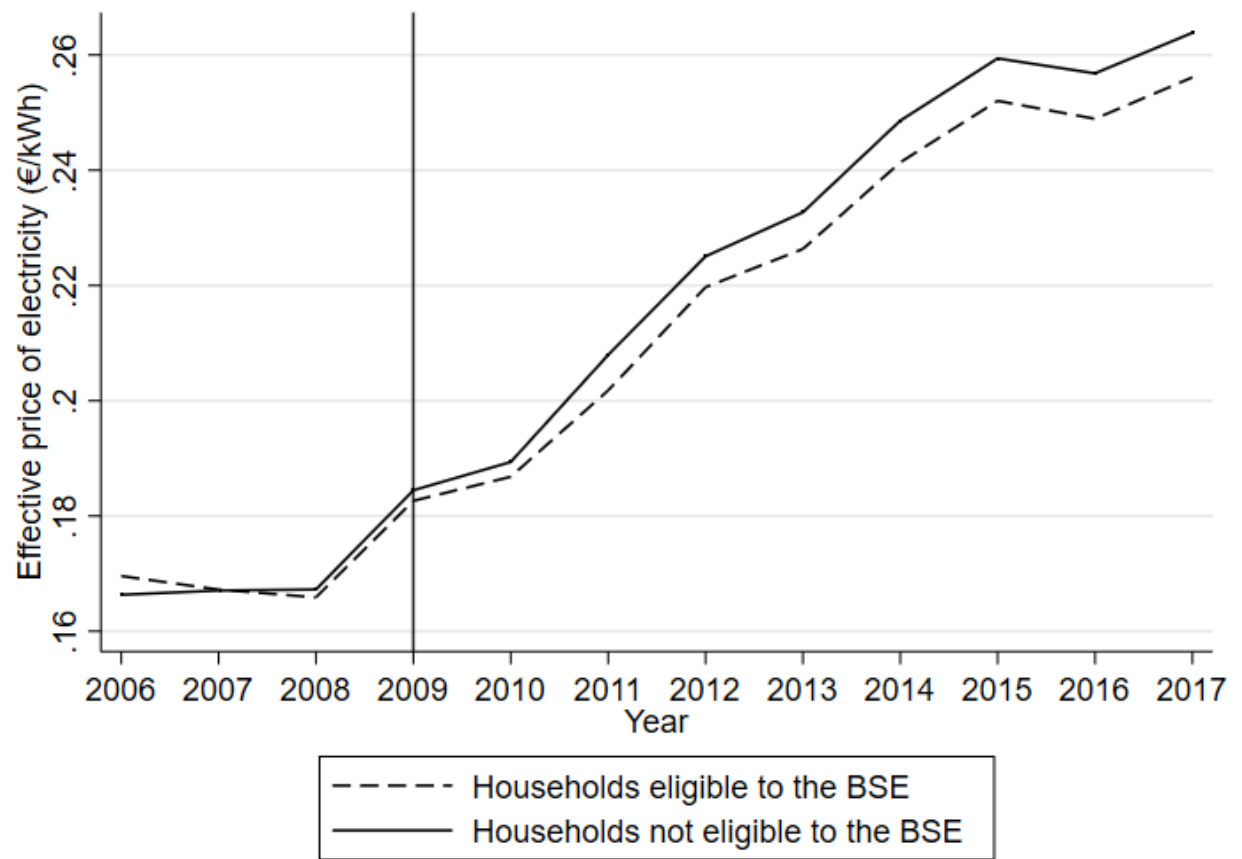

Note: The effective price is indexed on IPC (base 2016)

Source: EPF 2006-2017

Figure 7: Evolution of effective electricity prices over time 


\subsection{Control variables}

Based on the literature identifying the main drivers of energy poverty or electricity expenditure (in particular Tirado Herrero et al. (2018), Mohr (2018) Costa-Campi et al. (2019), and García Alvarez and Tol (2020)) we include a set of household and dwelling characteristics as controls. The goal of this inclusion is twofold: first, it allows to identify the impact of the $B S E$ on energy poverty while controlling as much as possible for energy needs, and avoiding any potential omitted variable. Second, the analysis of the coefficients of these variables is interesting per se, as it allows to identify which households are particularly vulnerable to energy poverty. This also allows to compare the results with those obtained by the existing literature.

In terms of household characteristics, we control for its size and its expenditure quintile. In terms of the household head characteristics we include the age, the gender, the marital status and the education level of the household head. ${ }^{11}$ Finally, in terms of dwelling characteristics, we include whether the dwelling is owned by its inhabitants, whether it is a flat, a detached house, a new construction, i.e. is less than 25 years old, whether it has heating, the number of rooms in the dwelling and finally its location, i.e. urban or rural. Table 2 provides with basic descriptive statistics of the control variables included in the analysis.

\section{Empirical strategy}

\subsection{Empirical framework}

To determine the causal impact of the introduction of the BSE in 2009 on the likelihood of energy poverty, we use a difference-in-differences methodology to estimate this effect through the simulation of an experimental design with observational study data. We compare the evolution of energy poverty before and after the introduction of the $B S E$ for those households that are eligible to it, relative to the evolution of energy poverty of the control group, i.e. households that do not meet the criteria for $B S E$ eligibility.

It is important to note that in our setting, since we are not able to explicitly identify households that actually subscribed to the $B S E$, we rely on the identification of eligible households. This means that instead of measuring the Average Treatment Effect (ATE), we measure the Intention to Treat (ITT) estimates. We therefore estimate the impact on being eligible to the $B S E$, and not the impact on actually receiving it.

Besides the necessity of using this estimator due to the structure of the data, this approach has several empirical advantages. First, while the criteria of $B S E$ eligibility are exogenously determined, the take-up of this subsidy is likely to be endogenous. Not focusing on the

\footnotetext{
${ }^{11}$ The household head is the member considered to earn the main income of the household.
} 


\begin{tabular}{lccc}
\hline & $\mathrm{N}$ & Mean & St. Dev. \\
\hline Controls: Household & & & \\
\hline Household size & 246,928 & 2.774 & 1.225 \\
Quintile & 246,928 & 3.000 & 1.414 \\
\hline Controls: Household head & & & \\
\hline H.Head Age & 246,928 & 54.30 & 14.86 \\
H.Head = Man & 246,928 & 0.716 & 0.451 \\
H.Head Marital status & & & \\
Single & 246,927 & 0.156 & 0.363 \\
Married & 246,927 & 0.655 & 0.475 \\
Widow & 246,927 & 0.113 & 0.316 \\
Separated & 246,927 & 0.030 & 0.170 \\
Divorced & 246,927 & 0.047 & 0.212 \\
H.Head Education & & & \\
No formal education, or below secondary & 246,928 & 0.238 & 0.426 \\
Secondary education, 1st cycle & 246,928 & 0.314 & 0.464 \\
Secondary education, 2nd cycle & 246,928 & 0.170 & 0.376 \\
Higher education & 246,928 & 0.278 & 0.448 \\
\hline Controls: Dwelling & & & \\
\hline Owning the dwelling & & & \\
Flat & 246,928 & 0.839 & 0.368 \\
Detached house & 246,928 & 0.640 & 0.480 \\
New dwelling & 246,928 & 0.113 & 0.316 \\
Heating & 246,834 & 0.361 & 0.480 \\
Number of rooms & 246,926 & 0.645 & 0.478 \\
Zone = Urban & 246,831 & 5.174 & 1.210 \\
\hline Averag ove $2006-2017.246$ & 0.809 & 0.393 \\
\hline
\end{tabular}

Average over 2006-2017. N: number of observations. St. Dev.: standard deviation.

Table 2: Summary statistics of control variables

take-up decision therefore allows to remove this non-random part of the analysis. Second, this approach is likely to lead to an under-estimation of the true effect of the social rate, since some households not subscribing to the $B S E$ are accounted for in the treatment group. Therefore, if we find any effect, the average treatment effects of the subscription are likely to be even larger. Finally, from a policy perspective, we estimate the effect of the introduction of the social rate in Spain on the population, rather than only estimating the effect for those who are benefiting from it. We therefore avoid over-optimistic conclusions that might arise if we omit that the introduction of the policy does not necessarily lead to a take-up of this policy.

One important assumption behind the difference-in-differences approach is the "parallel trend' assumption. In other words, we assume that without the introduction of the $B S E$, 
both treatment and control groups would have followed the same trend in terms of the dependent variable. It allows the treatment and control groups to be different, but this difference needs to be constant over time in absence of the treatment. This allows to rely on the control group as a counterfactual that informs us of what would have happened to households eligible to the $B S E$ in absence of the introduction of the policy, and compare it to the actual energy poverty of eligible households after the introduction of the policy.

To assess the validity of this assumption we present the evolution of the shares of households in energy poverty for both groups in Figure 8. A vertical line in 2009 represents the year of introduction of the BSE. For the parallel trend assumption to hold, both treatment and control groups should have a parallel trend before the policy. This seems to hold according to Figure 8. The graph also offers a first intuition at the reduction of the difference between the treatment and the control groups in the BSE-period (i.e. from 2009 onward).

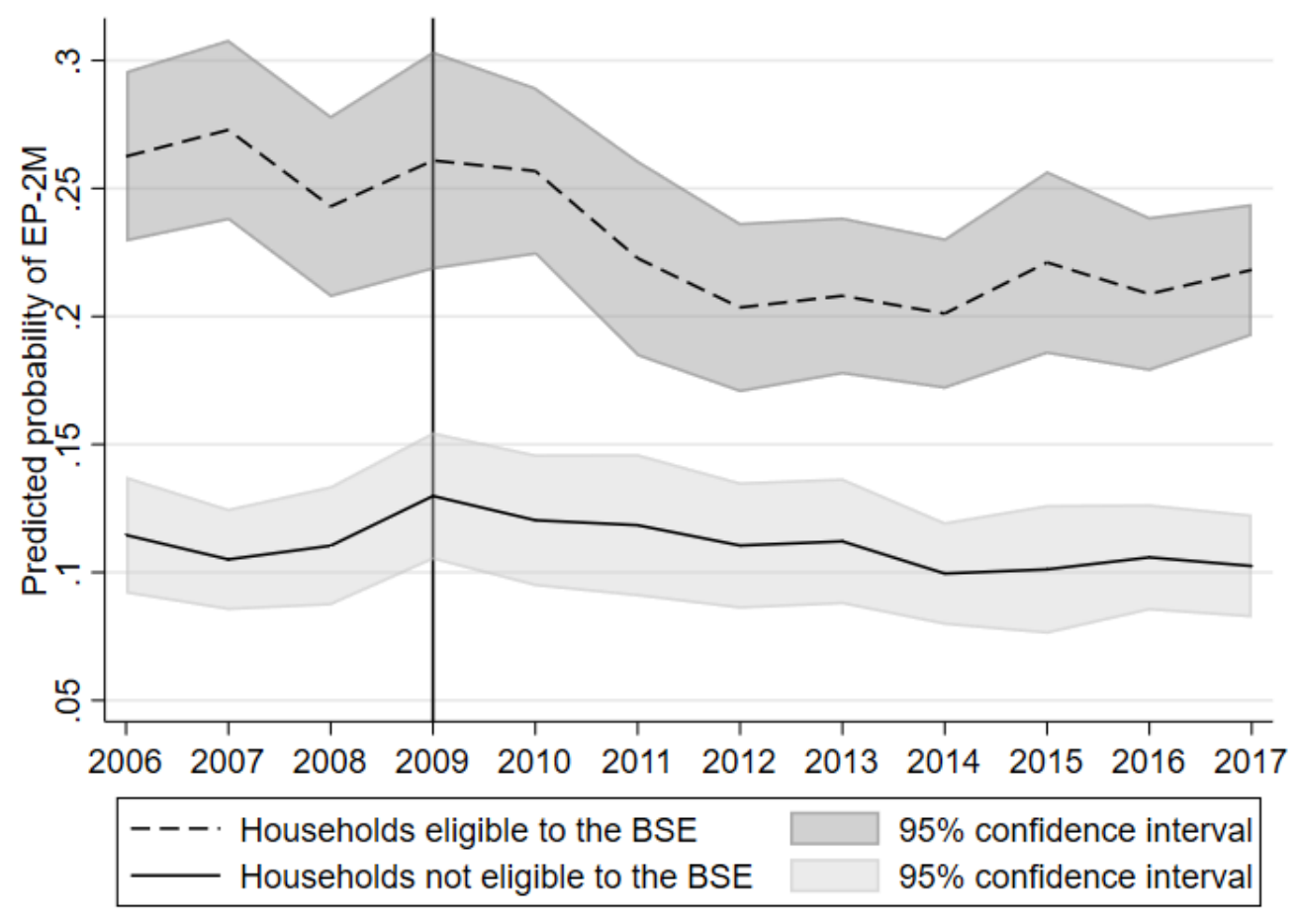

Source: EPF 2006-2017

Figure 8: Parallel trend assumption - Evolution of EP-2M over time

\subsection{Difference-in-differences model}

The main difference-in-differences (DiD) model is presented in Equation 1. 


$$
Y_{i j t}=\beta_{0}+\beta_{1} \text { BSEtreatment }_{j}+\beta_{2} \text { Post }_{t}+\beta_{3} \text { BSEtreatment }_{j} * \text { Post }_{t}+\beta_{4} X_{i j t}+\varepsilon_{i j t}
$$

Where $Y_{i j t}$, the outcome of interest, is the energy poverty status of household $i$ in treatment group $j$ ( $j=1$ if the household is eligible to BSE, the treatment group, and $j=0$ if it is in the control group) in year $t(t=2006, \ldots 2017)$.

$$
\begin{aligned}
& \text { BSEtreatment }_{j}=\left\{\begin{array}{lllc}
0 & \text { if } & j=0 & \text { (Not eligible to BSE) } \\
1 & \text { if } & j=1 & \text { (Eligible to BSE) }
\end{array}\right. \\
& \text { Post }_{t}=\left\{\begin{array}{lll}
0 & \text { if } & t<2009 \\
1 & \text { if } \quad t \geqslant 2009 & \text { (Before the introduction of the BSE) } \\
\text { (After the introduction of the BSE) }
\end{array}\right.
\end{aligned}
$$

$\beta_{3}$ is the coefficient of interest as it represent the effect of introducing the $B S E$ on the eligible households. $X_{i j t}$ are household-specific characteristics that include controls about the household, the household head and the dwelling.

Based on this model, in section 5 we systematically present five different specifications. In the first specification, we estimate the model as in Equation 1, but without any control variables, to be able to capture the average relationship between the $B S E$ and the outcome of interest. Second, we add the household-specific control variables, $X_{i j t}$, which include controls about the household, the household head and the dwelling. Third, to account for the time and regional variation shown in section 2 , we add to the previous specification two additional features: a linear year trend that captures changes that evolve linearly over the time frame in our data as well as regional fixed effects to account for any time-invariant specific regional characteristics. In the fourth model, we still account for household-specific control variables and regional fixed effects, but we replace the linear time trend by year fixed effects to account for regional-invariant effects that might occur over the years, not necessarily in a linear pattern. Finally, the fifth specification replaces region fixed effects and year fixed effects by region-year fixed effects that account for any characteristic that might affect a region in a specific year. This means that in the fifth specification, the year fixed effects can change over regions, or conversely, that the region fixed effects can change over time. In all the specifications the standard errors are clustered at the region-year level to account for the correlation of shocks that might occur within a region in a given year. Each of these specifications is considered to be more robust than the previous ones.

In the main analysis, the outcome of interest is the dummy variable determining whether the household is in a situation of energy poverty. In this case, we estimate the regression with a linear probability model. In section 5.2 , we investigate the mechanisms in which the 
$B S E$ directly affected households. To do so, we look at three additional variables. First, we look at the effective price of electricity faced by the households, second, we consider the quantities of electricity purchased and finally the expenditure in electricity. The model for effective prices is a linear model. Both quantities and expenditures are measured in logarithms to correct for their skeweness, and the regressions are thus estimated with a log-linear model.

\section{Results}

This section first presents and describes the difference-in-differences model measuring the causal effect of the introduction of the BSE on household energy poverty. The second subsection looks then at how the $B S E$ directly affected households and their consumption behavior, by looking at its effect on the effective electricity price faced by households, the quantities of electricity purchased, and the expenditure in electricity.

\subsection{The impact of the $B S E$ on energy poverty}

In this subsection we present the results of the main model, namely, the model measuring the effect of the introduction of the $B S E$ on energy poverty. As explained in section 4, given the structure of the data, we are measuring the causal effect of households being eligible to the $B S E$ on their likelihood of energy poverty.

The most important result is that the DiD estimator shows a negative and significant coefficient in all the specifications of the model, see Table 3. This means that the introduction of the BSE in 2009 caused a reduction in the likelihood of energy poverty among eligible households. Furthermore, this significant effect is robust to the inclusion of both household and dwelling controls, as well as to the introduction of a year trend and region, year, and region-year fixed effects. The magnitude of the effect is reduced once we include the household and dwelling control variables, but remains quite stable whatever the way we control for time and regional differences. This means that part of the decrease in a household's likelihood of energy poverty observed on average, is driven by other factors than the introduction of the policy. Still, the BSE has a significant role in the alleviation of energy poverty for the eligible households.

The interpretation of the magnitude of the effect of the $B S E$ on energy poverty is as follows: the introduction of the $B S E$ in Spain has reduced the probability of energy poverty of eligible households by around 2 percentage points over the period with respect to a situation in which the $B S E$ had not been introduced. In practice, this implies that around 59,000 households are no longer in a situation of energy poverty as a result of the introduction of the $B S E .^{12}$ Even though it is a lower bound, the magnitude of this effect is very low as it

\footnotetext{
${ }^{12}$ To be able to get this number, we first know that out of the 18.5 million households in Spain, $15.95 \%$
} 


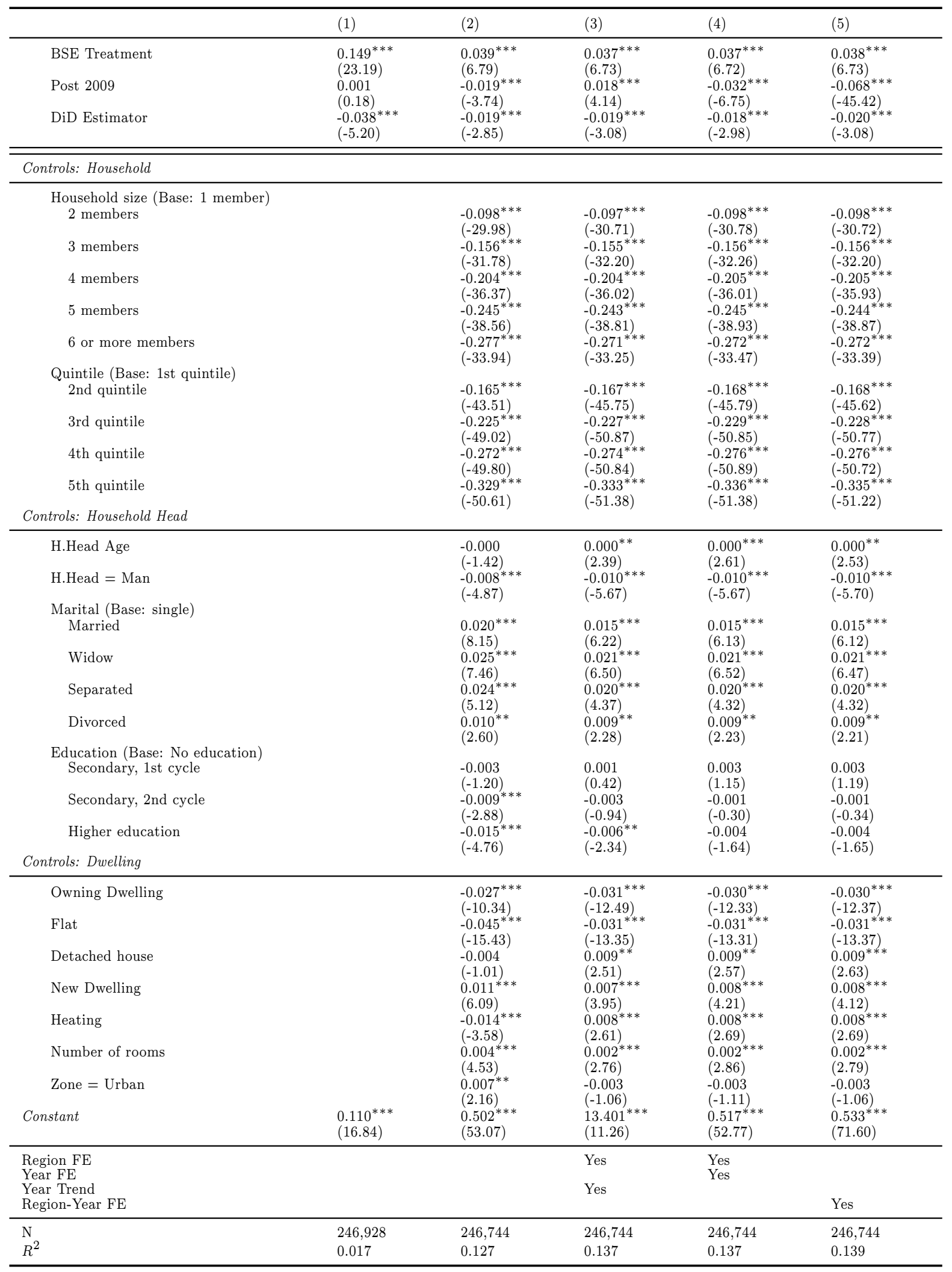

Robust standard errors in parentheses clustered by region and year - FE: fixed effects $*, * *, * * *$ denote significance at the 10 percent, 5 percent and 1 percent levels respectively

Table 3: Difference-in-differences - Dependent variable: EP2M 
corresponds to only $7.7 \%$ of eligible households who were in energy poverty before 2009 .

In terms of control variables, our results are intuitive with respect to the links between energy poverty and household, household head and dwelling characteristics and reconcile with the literature. First, in terms of household variables, household size shows a robust significant and increasingly negative coefficient. In other words, larger households in terms of number of members are associated with a lower probability of energy poverty compared to a household of only one member. This suggests that single-member households are highly vulnerable. The same conclusion holds for the expenditure quintile. Intuitively, the higher the quintile, the lower the probability of being in a situation of energy poverty.

Second, concerning the role played by the household head, age is significant when including region and year fixed effects, albeit the effect is small. Moreover, having a man rather than a woman as household head is associated with a lower probability of energy poverty. The marital status shows a highly significant effect. Keeping the household size fixed, any marital status, married, widow, separated or divorced, is associated with a higher probability of energy poverty compared to a household head being single. And finally, the results give evidence of a link between education and energy poverty: the higher the education level of the household head, the lower the probability of energy poverty. This result is however not robust to the inclusion of region and year fixed effects.

Third, concerning dwelling characteristics, owning the dwelling and living in a flat are significantly and robustly associated with a lower probability of energy poverty. Intuitively, owning the home is linked with higher income levels, while living in a flat rather than a house is linked with lower expenditure needs, because of isolation issues. Similarly, living in a detached house, in a new dwelling, with heating or having a higher number of rooms are significantly associated with a higher probability of energy poverty. Finally, living in an urban area rather than a rural one, is associated with a higher probability of energy poverty, though the result is not robust to the inclusion of the year trend or regional and year fixed effects. The $R^{2}$ shows how important it is to include household and dwelling characteristics in the analysis, as the goodness-of-fit jumps from $1.7 \%$ to between $12.7 \%$ when doing so.

Fourth, the inclusion of controls for spatial and temporal heterogeneity is important as well since the goodness-of-fit further increases. As expected, each specification is more robust that the previous one. In other words, the best model is the one in which region fixed effects are allowed to differ over time, or conversely that time fixed effects are allowed to differ over regions. This suggest that regions the evolution of energy poverty has followed different trajectories in the different regions over the time period. Moreover, these results

of them are eligible to the $B S E$. This corresponds to almost 3 million vulnerable households eligible for the $B S E$, out of which 2 percent are no longer in a situation of energy poverty. Data on the number of households in Spain for 2017. 
suggest that even though the different regions in Spain have different base levels of energy poverty, and even though they have implemented different regional policies, this is not enough to explain the effectiveness of the BSE. In other words, even when all regional, and yearly-regional, differences are accounted for, the $B S E$ is still significantly decreasing the likelihood of energy poverty in Spain.

\subsection{Mechanisms}

As we have just shown that the introduction of the $B S E$ has significantly and robustly decreased the likelihood of energy poverty, we now analyze the different mechanisms through which the subsidy affects households directly. In particular, we investigate on the impact of the $B S E$ on three variables, namely the effective price of electricity, the quantities purchased and the total expenditure in electricity. We first discuss the mechanism from a theoretical perspective and then, we review the results.

\subsubsection{Theoretical framework}

The $B S E$ is a subsidy implying a discount on price of electricity for eligible consumers. The explicit goal of this subsidy is to increase the affordability of electricity for vulnerable consumers. There is no explicit willingness to change consumption behavior with this type of subsidy. By opposition for instance to a subsidy that would aim at correcting for some type of market failure by inducing a change in consumption behavior. This would be, for example, to account for the positive externalities related with the use of renewable energies.

We must consider however that when a subsidy targets the affordability of a good, this increased affordability can have indirect effects. Indeed, considering that a subsidy is a reduction in the effective price, this in turn can have an effect on the consumption behavior of the consumer. If we consider the partial equilibrium with only the subsidized good, a reduction of effective price would increase its consumption for any type of normal good. Once we consider more general equilibria and budget allocations, this might be less obvious. When the effective price of one of the goods consumed decreases, the household can decide to increase the consumption of this particular good, or to keep the consumption constant and to reallocate the additional resources to the consumption of other goods, or even any mix of the two previous scenarios.

Coming back to the specific purpose of this paper, the $B S E$ was introduced in Spain in 2009 in order to increase the affordability of electricity for vulnerable consumers. We therefore expect a reduction in the effective price of electricity faced by eligible households. How these households would react in terms of their consumption behavior to the reduced effective price is however less predictable. If, in the absence of the subsidy, households are rationing their electricity consumption, resulting for instance in an inability to keep the dwelling adequately 
warm, an increase in the quantity of electricity purchased could be expected. If on the other hand, we do not observe a change in the consumption behavior following the introduction of the $B S E$, we could either conclude that on average there is no rationing in electricity, or that even if households would appreciate to consume more electricity, they decide to allocate the new resources to other ends. Whatever the reason of the consumption behavior, the results obtained in the analysis can be interpreted as revealed preferences of households.

Finally, as expenditure in electricity is by definition the effective price multiplied by the quantity consumed, the expected effect of the $B S E$ on electricity expenditure depends on the reaction of consumption to the reduced effective price. We can however explicit the two extreme scenarios. The first scenario is the one in which the increased affordability of electricity does not affect the consumption behavior. In other words, this is the scenario in which the subsidy reduces the effective price of electricity, which releases a new budget completely allocated to other goods, leaving the quantity of electricity consumed unchanged. The second extreme scenario is the one in which this new budget resulting from a decrease in effective price is exclusively used for increasing the consumption of electricity, and therefore leaving the total expenditure in electricity unchanged. There are also a continuum of other scenarios in between these two extremes. The goal of the next section is to empirically check each of these three effects.

\subsubsection{Results}

In this section we empirically test three potential effects suggested by theory: the impact of the $B S E$ on the effective price of electricity, its impact on the quantities of electricity purchased and finally on the expenditure in electricity. We do so by estimating the same five specifications described in section 4 in terms of the inclusion of household and dwelling controls, year trends as well as region and year fixed effects. Since expenditure and quantities are considerably skewed, we measure both effects on the logarithms of such variables.

The first result is that $B S E$ significantly decreases the effective price of electricity for eligible consumers. The DiD estimator in Table 4 shows a negative and significant coefficient in every specification of the model, thus being robust to the inclusion of household and dwelling controls as well as year trends and regional and year fixed-effects. This confirms the hypothesis presented in the previous section, and intuitively, this result reconciles with the way in which the social rate is implemented as it entails a reduction in the price faced by vulnerable consumers. More precisely, the introduction of the $B S E$ reduces the effective price faced by eligible households by $0.005 € / \mathrm{kWh}$. With respect to the average effective price of eligible households before 2009, this represents a reduction of $3 \%$.

The second result is that the $B S E$ does not change the consumption behavior of households in terms of quantities of electricity purchased. Table 5 shows the coefficients of the estima- 


\begin{tabular}{llllll}
\hline & $(1)$ & $(2)$ & $(3)$ & $(4)$ & $(5)$ \\
\hline BSE Treatment & 0.001 & $0.002^{* *}$ & $0.003^{* * *}$ & $0.003^{* * *}$ & $0.003^{* * *}$ \\
& $(0.75)$ & $(2.05)$ & $(4.43)$ & $(5.30)$ & $(5.09)$ \\
Post 2009 & $0.063^{* * *}$ & $0.060^{* * *}$ & 0.001 & $0.095^{* * *}$ & $0.094^{* * *}$ \\
& $(20.78)$ & $(20.53)$ & $(0.37)$ & $(29.81)$ & $(610.03)$ \\
DiD Estimator & $-0.007^{* * *}$ & $-0.005^{* * *}$ & $-0.005^{* * *}$ & $-0.005^{* * *}$ & $-0.005^{* * *}$ \\
& $(-4.98)$ & $(-4.04)$ & $(-5.41)$ & $(-6.95)$ & $(-7.05)$ \\
\hline Household Controls & & Yes & Yes & Yes & Yes \\
Dwelling Controls & & Yes & Yes & Yes & Yes \\
\hline Region FE & & & Yes & Yes & \\
Year FE & & & & Yes & \\
Year Trend & & & Yes & & Yes \\
Region-year FE & & & & & 246,744 \\
N & 246,928 & 246,744 & 246,744 & 246,744 & 0.502 \\
$R^{2}$ & 0.232 & 0.254 & 0.465 & 0.481 & 0.451 \\
\hline
\end{tabular}

Robust standard errors in parentheses clustered by region and year - FE: fixed effects

$*, * *, * * *$ denote significance at the 10 percent, 5 percent and 1 percent levels respectively

Table 4: Difference-in-differences - Dependent variable: Effective Prices of Electricity

tion when the dependent variable is the logarithm of the quantity of electricity consumed by households. We can see that the $B S E$ did not have any robust effect on the quantity of electricity consumed by the households. The first specification of the model does suggest a positive coefficient of the DiD estimator, but the result is not robust to the inclusion of control variables and fixed effects. This means that, even though we might observe an average increase in the consumption of electricity for eligible households after 2009, the increase is entirely captured by households or dwelling characteristics, or by fixed effects.

These results are particularly striking as they suggest that we are in one of the two extreme scenarios presented in the previous section. In other words, the introduction of the BSE did reduce the effective price of electricity faced by consumers, but this did not induce a change in consumption behavior in terms of quantities of electricity purchased. To put it differently, the results can be seen as a revealed preference mechanism showing that households prefer to spend the additional budget on other goods instead of electricity.

Finally, the third result shows that the $B S E$ significantly decreases the total expenditure in electricity for eligible households, as it could be expected once we have seen the first and second results. Table 6 shows the results for the model in which the dependent variable is the logarithm of the expenditure in electricity. The coefficient is significant and negative in the fifth specification of the model, which is the most robust one as we include household and dwelling characteristics, and region-year fixed effects. In this case, the introduction of the 


\begin{tabular}{llllll}
\hline & $(1)$ & $(2)$ & $(3)$ & $(4)$ & $(5)$ \\
\hline BSE Treatment & $-0.193^{* * *}$ & $-0.060^{* * *}$ & $-0.068^{* * *}$ & $-0.069^{* * *}$ & $-0.064^{* * *}$ \\
& $(-11.09)$ & $(-5.62)$ & $(-7.34)$ & $(-7.77)$ & $(-7.17)$ \\
Post 2009 & $-0.041^{*}$ & 0.011 & $0.191^{* * *}$ & $-0.090^{* * *}$ & $-0.108^{* * *}$ \\
& $(-1.84)$ & $(0.67)$ & $(8.60)$ & $(-5.67)$ & $(-45.42)$ \\
DiD Estimator & $0.092^{* * *}$ & 0.017 & 0.014 & 0.012 & 0.006 \\
& $(4.73)$ & $(1.33)$ & $(1.35)$ & $(1.21)$ & $(0.58)$ \\
\hline Household Controls & & Yes & Yes & Yes & Yes \\
Dwelling Controls & & Yes & Yes & Yes & Yes \\
Region FE & & & Yes & Yes & \\
Year FE & & & & Yes & \\
Year Trend & & & Yes & & Yes \\
Region-year FE & & & & & 246,744 \\
N & 246,928 & 246,744 & 246,744 & 246,744 & 0.266 \\
$R^{2}$ & 0.006 & 0.205 & 0.251 & 0.261 & 0.251 \\
\hline
\end{tabular}

Robust standard errors in parentheses clustered by region and year - FE: fixed effects $*, * *, * * *$ denote significance at the 10 percent, 5 percent and 1 percent levels respectively

Table 5: Difference-in-differences - Dependent variable: Logarithm of Quantity of Electricity Consumed

\begin{tabular}{llllll}
\hline & $(1)$ & $(2)$ & $(3)$ & $(4)$ & $(5)$ \\
\hline BSE Treatment & $-0.193^{* * *}$ & $-0.049^{* * *}$ & $-0.052^{* * *}$ & $-0.053^{* * *}$ & $-0.048^{* * *}$ \\
& $(-12.92)$ & $(-5.49)$ & $(-6.89)$ & $(-7.24)$ & $(-6.58)$ \\
Post 2009 & $0.269^{* * *}$ & $0.308^{* * *}$ & $0.224^{* * *}$ & $0.364^{* * *}$ & $0.343^{* * *}$ \\
& $(15.54)$ & $(20.37)$ & $(10.36)$ & $(43.73)$ & $(166.68)$ \\
DiD Estimator & $0.060^{* * *}$ & -0.008 & -0.009 & -0.013 & $-0.018^{* *}$ \\
& $(3.63)$ & $(-0.77)$ & $(-1.09)$ & $(-1.51)$ & $(-2.14)$ \\
\hline Household Controls & & Yes & Yes & Yes & Yes \\
Dwelling Controls & & Yes & Yes & Yes & Yes \\
Region FE & & & Yes & Yes & \\
Year FE & & & & Yes & \\
Year Trend & & & Yes & & Yes \\
Region-year FE & & & & & 246,744 \\
N & 246,928 & 246,744 & 246,744 & 246,744 & 290 \\
$R^{2}$ & 0.054 & 0.252 & 0.280 & 0.290 & 0.292 \\
\hline
\end{tabular}

Robust standard errors in parentheses clustered by region and year - FE: fixed effects $*, * *, * * *$ denote significance at the 10 percent, 5 percent and 1 percent levels respectively

Table 6: Difference-in-differences - Dependent variable: Logarithm of Expenditure in Electricity 
$B S E$ causes the expenditure in electricity of eligible households to decrease by $1.78 \% .{ }^{13}$ Note that without including the control variables and the fixed effects, we might have concluded the opposite effect. Indeed, specification 1, i.e. the specification in which household and dwelling characteristics are not controlled for and fixed effects and year trends are not included, shows a positive and significant effect on the logarithm of monetary expenditure in electricity. However the goodness-of-fit increases significantly when including the different controls, a year trend and fixed effects, jumping from 0.05 in specification 1 , to between 0.25 and 0.29 in the other ones. We can therefore conclude that the introduction of the BSE reduces the household expenditure in electricity. This is in line with the two previous results, namely that $B S E$ caused a reduction in the effective price of electricity but no change in consumption behavior. The entire effect of this subsidy policy is therefore channeled through an increased affordability that reduces expenditures in electricity and releases a budget to be spent on other goods.

The goodness-of-fit of the three models is also worth analyzing, as it suggests that control variables are important, but that their relative importance depends on the outcome variable. Indeed, when we look at the effective price of electricity (Table 4), adding socio-economic and dwelling variables does not improve the goodness-of-fit of the model by much (going from $23.2 \%$ to $25.4 \%$ ). Conversely, controlling for region and time effect substantially increases the $R^{2}$ (to between $46.5 \%$ and $50.2 \%$ ). Indeed, the characteristics of the household or the dwelling in which they live should not have a direct effect on the price they face, hence the low explanatory power of these control variables. For the specification about quantities, we observe a different pattern. In fact, quantities consumed are more directly dependent on household and dwelling characteristics, which is reflected in the increase of the goodness-of-fit between specifications (1) and (2) in Table 5, where the $R^{2}$ increases from $0.6 \%$ to $20.5 \%$ when including household and dwelling controls. The goodness-offit for the quantities purchased does not further increase by much when controlling for regional and temporal variation. As a result, it can be expected that household and dwelling controls improve the goodness-of-fit of the expenditure model, since expenditure involves quantities. Table 6 further confirms this prediction, as the $R^{2}$ jumps from $5.4 \%$ to $25.2 \%$ when including household and dwelling controls. This analysis suggests that household and dwelling variable are more powerful in the prediction quantities of electricity purchased and the expenditure in electricity than in the prediction of the effective price faced by households. Conversely, controlling for regional and temporal differences is more important to predict prices than quantities and expenditures.

In sum, the $B S E$ does indeed have a direct effect on households. It statistically significantly decreases the effective price of electricity that these households face. In response to this lower effective price, the households do not increase the quantity of electricity consumed and

\footnotetext{
${ }^{13}$ For specification $(5):\left(e^{-0.018}-1\right) * 100=-1.78 \%$
} 
therefore the entire effect is channeled through a reduction in the expenditure in electricity. This increased affordability of electricity does therefore not imply a change of consumption behavior for electricity. Thus, even if some household may be in a situation in which they ration on their consumption of electricity, these revealed preferences suggest that either on average there is not much rationing, or that even with rationing, households prefer to allocate this additional budget to other expenses.

\section{Robustness checks}

\subsection{Alternative measures of energy poverty}

In this section, we test whether our results on energy poverty hold when we use alternative indicators.

\subsubsection{Alternative indicator: Hidden energy poverty}

As the definition of energy poverty is quite broad, different indicators are used in practice. In the analysis we have focused on one indicator: EP-2M, which classifies households as in energy poverty if their share of expenditure on electricity is above twice the national median. This measure captures households that allocate an unusually high share of expenditure to electricity. There are however alternative objective indicators that reflect a different aspect of energy poverty. In particular, there exists the concept of hidden energy poverty (HEP) that identifies households whose electricity spending is "abnormally low", which might indicate restricted spending. This is also an objective indicator as it is based on expenditure levels rather than self-reported measures, and it is included, with EP-2M, as one of the most important indicators of energy poverty (Rademaekers et al., 2016). ${ }^{14} \mathrm{~A}$ household is therefore considered to be in hidden energy poverty if its electricity expenditure are below half the national median. In our sample, on average $9 \%$ of households are in HEP and there is a significant and positive correlation between HEP and BSE eligibility (see Appendix C for the descriptive statistics).

The goal of this section is to check whether the $B S E$ also has an effect on the hidden energy poverty. This is indeed validated in Table 7 , as the table shows that the introduction of the $B S E$ significantly reduces the likelihood of HEP by 1 to 1.2 percentage points. This corresponds to an additional 29,500 households that go out of energy poverty because of the $B S E$. In other words, the effectiveness of the $B S E$ on reducing energy poverty is robust to whether the indicator looks at households who spend a too large share of their expenditure

\footnotetext{
${ }^{14}$ It is important to note that contrary to EP-2M, HEP has to be constructed using the absolute monetary expenditure rather than the share of expenditure spent on electricity. Indeed, as hinted in Figure 2, lower income households spend on average less on electricity in absolute value, but more as a share of their expenditure. Therefore, using absolute expenditure allows to identify households that spend an abnormally low amount of expenditure on electricity.
} 
on electricity or whether it looks at households who have abnormally low levels of electricity expenditure.

\begin{tabular}{llllll}
\hline & $(1)$ & $(2)$ & $(3)$ & $(4)$ & $(5)$ \\
\hline BSE Treatment & $0.102^{* * *}$ & $0.040^{* * *}$ & $0.040^{* * *}$ & $0.040^{* * *}$ & $0.038^{* * *}$ \\
& $(13.80)$ & $(7.08)$ & $(7.51)$ & $(7.55)$ & $(7.25)$ \\
Post & $0.019^{* * *}$ & $0.006^{*}$ & $0.039^{* * *}$ & $-0.018^{* * *}$ & $-0.009^{* * *}$ \\
& $(5.75)$ & $(1.92)$ & $(11.88)$ & $(-4.09)$ & $(-6.71)$ \\
DiD Estimator & $-0.041^{* * *}$ & $-0.012^{*}$ & $-0.012^{* *}$ & $-0.012^{* *}$ & $-0.010^{*}$ \\
& $(-5.03)$ & $(-1.89)$ & $(-1.99)$ & $(-2.06)$ & $(-1.71)$ \\
\hline Household Controls & & Yes & Yes & Yes & Yes \\
Dwelling Controls & & Yes & Yes & Yes & Yes \\
\hline Region FE & & & Yes & Yes & \\
Year FE & & & & Yes & \\
Year Trend & & & Yes & & Yes \\
Region-year FE & & & & & 246,744 \\
N & 246,928 & 246,744 & 246,744 & 246,744 & 0.110 \\
$R^{2}$ & 0.009 & 0.102 & 0.108 & 0.108 & 0.108 \\
\hline
\end{tabular}

Robust standard errors in parentheses clustered by region and year - FE: fixed effects

$*,{ }^{* *},{ }^{* * *}$ denote significance at the 10 percent, 5 percent and 1 percent levels respectively

Table 7: Difference-in-differences - Dependent variable: Hidden Energy Poverty

\subsubsection{Sensitivity analysis to the threshold for EP-2M}

The indicator we have used, EP-2M, classifies households as in energy poverty if their share of expenditure spent on electricity is above twice the national median. The goal of this section is to conduct a sensitivity analysis to the threshold, i.e. twice the median, in order to check whether the results are robust to this choice. To do so, we construct different measures of energy poverty according to different thresholds being $X$ times the median, with $X=\{1,1.25,1.5, \ldots 3\}$.

We confirm that our result are robust to the choice of the threshold in Figure 9. It shows that for all thresholds between 1.75 times the median and 3 times the median, the introduction of the BSE reduces the likelihood of energy poverty at the $95 \%$ significance level. The main results are therefore not dependent on the specific choice of twice the median. See Appendix D for the complete table of the results. 


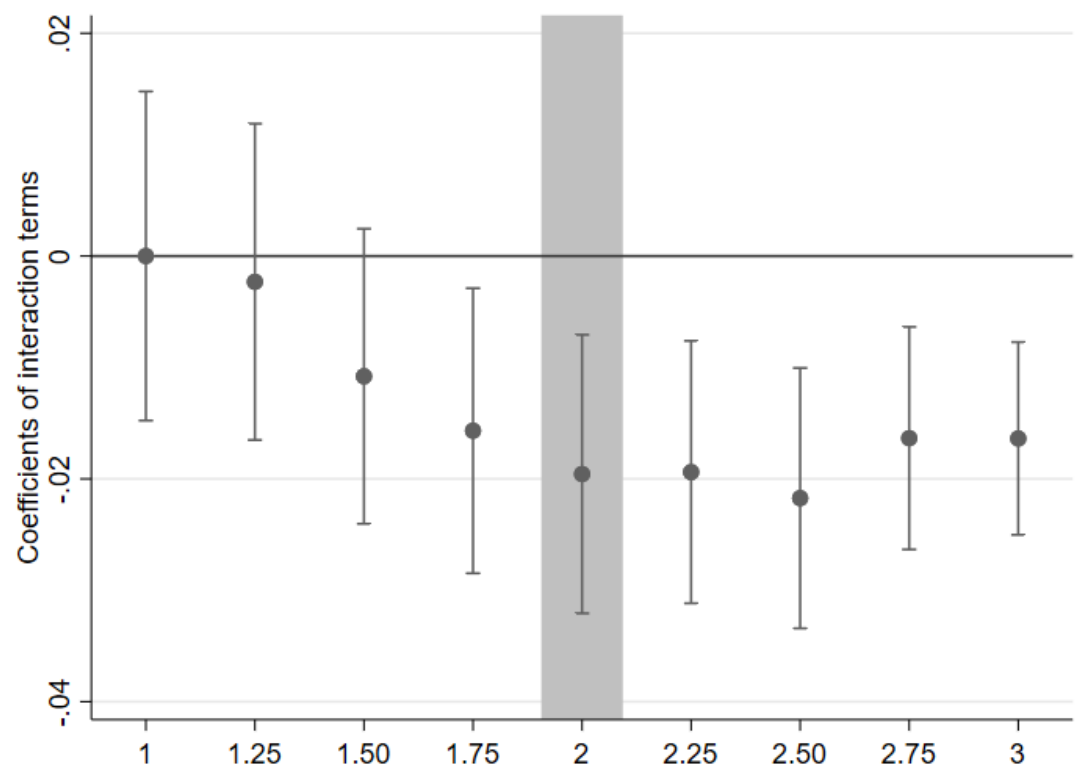

Threshold for energy poverty: above $X$ times the national median of that year

Note: Each point represents the estimated coefficient of the interaction between the BSE Treatment dummy and the Post 2009 dummy in the specification that includes household controls, dwelling controls and region-year fixed effects (i.e. specification 5). The error bars represent the $95 \%$ confidence interval, with robust standard errors clustered by region and year. The shaded area corresponds to the baseline EP-2M.

Source: EPF 2006-2017

Figure 9: Sensitivity analysis to the threshold for Energy Poverty

\subsubsection{Restrict the sample to low-income households}

An important debate related to the choice of indicator is about the population that can be considered as being in energy poverty. Some countries prefer to consider only low income households in their official metrics. For instance, Belgium's official indicator is EP-2M, but restricted only to the five lower deciles of the income distribution (Rademaekers et al., 2016). In this section, we check whether our results hold when considering only the bottom half sample in terms of income. ${ }^{15}$

First, almost all of the vulnerable households according to the $B S E$ are among the lower income sample. Eligible households to the social rate correspond to nearly $30 \%$ of the lowerincome households, while they correspond only to $2 \%$ of the higher-income households. Second, $19 \%$ of lower-income households are in energy poverty, while this figure decreases

\footnotetext{
${ }^{15}$ As recommended by (Rademaekers et al., 2016), we consider the equivalized income. In other words, we normalize the household income to its size, considering for the age distribution. The first adult has a weight of 1 , then any additional adult has a weight of 0.5 to account for economies of scale, and any additional child has a weight of 0.3 .
} 
to $7 \%$ for the higher income households.

Table 8 presents the results of the impact of $B S E$ eligibility among the five lowest deciles of the income distribution. It confirms that the $B S E$ significantly reduces the likelihood of energy poverty for the eligible households. In terms of magnitude, it is a 1.8 percentage point decrease, which corresponds to a $6.4 \%$ decrease with respect to the average among eligible households before 2009. The result from our baseline model is therefore similar to the one obtained when we consider only lower-income households.

\begin{tabular}{llllll}
\hline & $(1)$ & $(2)$ & $(3)$ & $(4)$ & $(5)$ \\
\hline BSE Treatment & $0.122^{* * *}$ & $0.031^{* * *}$ & $0.030^{* * *}$ & $0.030^{* * *}$ & $0.031^{* * *}$ \\
& $(18.30)$ & $(5.42)$ & $(5.24)$ & $(5.22)$ & $(5.38)$ \\
Post & 0.010 & $-0.022^{* * *}$ & $0.017^{* * *}$ & $-0.031^{* * *}$ & $-0.073^{* * *}$ \\
& $(1.23)$ & $(-3.38)$ & $(2.64)$ & $(-3.96)$ & $(-32.20)$ \\
DiD Estimator & $-0.055^{* * *}$ & $-0.016^{* *}$ & $-0.017^{* * *}$ & $-0.016^{* *}$ & $-0.018^{* * *}$ \\
& $(-7.33)$ & $(-2.48)$ & $(-2.61)$ & $(-2.49)$ & $(-2.71)$ \\
\hline Household Controls & & Yes & Yes & Yes & Yes \\
Dwelling Controls & & Yes & Yes & Yes & Yes \\
\hline Region FE & & & Yes & Yes & \\
Year FE & & & & Yes & \\
Year Trend & & & Yes & & \\
Region-year FE & & & & & Yes \\
\hline N & 123,468 & 123,365 & 123,365 & 123,365 & 123,365 \\
$R^{2}$ & 0.009 & 0.115 & 0.125 & 0.126 & 0.128 \\
\hline
\end{tabular}

Robust standard errors in parentheses clustered by region and year - FE: fixed effects $*, * *, * * *$ denote significance at the 10 percent, 5 percent and 1 percent levels respectively. Lowerhouseholds correspond to the lowest five deciles in terms of equivalized income.

Table 8: Difference-in-differences - Energy poverty among lower-income households

\subsection{The effect of BSE on income poverty}

Income poverty is a distinct issue from energy poverty. However, the introduction of the $B S E$ could also have had an effect on income poverty since, as our results have shown, the social subsidy has an effect on expenditure through lower effective prices, thus liberating a share of income. In this subsection, we analyze whether the introduction of the BSE has had an effect on eligible household's likelihood of being in income poverty.

First, Table 9 presents the distribution of households according to these two measures, i.e. energy and income poverty. It confirms that while $13 \%$ of the sample is in energy poverty, only $4.6 \%$ are also in income poverty. Each of these issues should therefore be treated separately from a policy perspective. 
Second, Table 10 presents the results of the estimations in which the dependent variable is income poverty. They show that households eligible to the $B S E$ have a lower probability of being in income poverty by 13.7 percentage points. Given that before 2009, $68 \%$ of eligible households were in income poverty, this corresponds to a $20 \%$ decrease.

\begin{tabular}{l|cc|c}
\hline \multirow{2}{*}{ Income poverty } & \multicolumn{2}{|c|}{ Energy Poverty } & \\
\hline \multirow{2}{*}{ No } & No & Yes & Total \\
& 180,629 & 20,690 & 201,319 \\
\multirow{2}{*}{ Yes } & $(73.15)$ & $(8.38)$ & $(81.53)$ \\
\hline \multirow{2}{*}{ Total } & 34,244 & 11,365 & 45,609 \\
& $(13.87)$ & $(4.60)$ & $(18.47)$ \\
\hline
\end{tabular}

Inside each cell: number of observations and cell frequency in parenthesis. Income poverty if the equivalized disposable income of the household is below $60 \%$ of the median of that year. Energy poverty if the share of electricity expenditure is above $2^{*}$ median of that year.

Table 9: Energy poverty and income poverty

\begin{tabular}{llllll}
\hline & $(1)$ & $(2)$ & $(3)$ & $(4)$ & $(5)$ \\
\hline BSE Treatment & $0.581^{* * *}$ & $0.506^{* * *}$ & $0.505^{* * *}$ & $0.505^{* * *}$ & $0.506^{* * *}$ \\
& $(77.91)$ & $(72.49)$ & $(70.96)$ & $(71.50)$ & $(68.30)$ \\
Post & 0.011 & $0.007^{*}$ & $-0.007^{*}$ & $0.036^{* * *}$ & $0.041^{* * *}$ \\
& $(1.29)$ & $(1.83)$ & $(-1.88)$ & $(6.79)$ & $(20.38)$ \\
DiD Estimator & $-0.128^{* * *}$ & $-0.135^{* * *}$ & $-0.136^{* * *}$ & $-0.136^{* * *}$ & $-0.137^{* * *}$ \\
& $(-13.41)$ & $(-15.41)$ & $(-15.40)$ & $(-15.50)$ & $(-15.07)$ \\
\hline Household Controls & & Yes & Yes & Yes & Yes \\
Dwelling Controls & & Yes & Yes & Yes & Yes \\
\hline Region FE & & & Yes & Yes & \\
Year FE & & & & Yes & \\
Year Trend & & & Yes & & Yes \\
Region-year FE & & & & & 246,744 \\
N & 246,928 & 246,744 & 246,744 & 246,744 & 0.337 \\
$R^{2}$ & 0.208 & 0.332 & 0.335 & 0.336 & 0.337 \\
\hline
\end{tabular}

Robust standard errors in parentheses clustered by region and year - FE: fixed effects

$*, * *, * * *$ denote significance at the 10 percent, 5 percent and 1 percent levels respectively

Table 10: Difference-in-differences - Dependent variable: Income Poverty 


\section{Policy evaluation}

In this section, we evaluate the $B S E$ as a policy measure introduced with the objective of reducing energy poverty in Spain, where 2.8 million households were in energy poverty in 2018 (Tirado Herrero et al., 2018). More precisely, we discuss the magnitude of the effect, the cost of the policy, and its targeting of beneficiaries.

First, the introduction of the $B S E$ in 2009 cannot be described as a success. Indeed, the results show that the introduction of the BSE in 2009 reduced, on average, the probability of being in energy poverty by 2 percentage points. In terms of comparisons, $26 \%$ of households eligible to the $B S E$ were in energy poverty before 2009. If this figure decreases by 2 percentage points, it corresponds a decline of $7.7 \%$. To put it differently, 59,000 families, which are those out of energy poverty as a result of the introduction of the BSE, are not enough when considering there are still 2.8 million families in a situation of energy poverty. It is positive that some families have managed to leave the energy poverty situation as a result of subscribing to the $B S E$, but it cannot be judged as a success, rather as a failure or a missed opportunity.

Second, it is also relevant to discuss the financing of the BSE. It has been advertised that no public spending was used to finance the BSE, suggesting that the private electric companies bear the whole cost. In practice, it is unlikely that the electric companies would accept such a deal. Instead, they can use two mechanisms to reduce the burden of the BSE. They can use cross-subsidies. This corresponds to a situation in which the electric companies would raise the price for other consumers, so that they indirectly subsidize the price reduction for the beneficiaries of the social rate. Another plausible way of financing the $B S E$, is for the government to lower the VAT rate on the electric companies. This allows companies to compensate for the losses due to the $B S E$, and for the government to state that there are no fiscal costs. This, however, would be inaccurate, as there would be foregone fiscal revenues. Overall, even though the policy has no official direct fiscal costs, it is plausible that it has important indirect costs, borne by consumers and the government. These should be made transparent to allow a more precise evaluation of the policy.

Finally, the objective of this paper is to measure the effectiveness of the $B S E$ as introduced in 2009 on a household's probability of being in energy poverty. It is important to keep in mind that this paper does not evaluate the policy targeting. The policy targeting has however been widely criticized since the introduction of the $B S E$ in 2009, particularly for not including criteria based on the household's income. For instance in 2009, the initial criteria included large families irrespective of their level of income, which allowed high income families to be eligible to the social rate if they had at least three children. As a result, the government modified the eligibility criteria of the $B S E$, and from 2018 it does 
include income. This suggests that the government was aware that the previous targeting had high risks of including households that are not the most vulnerable.

It is important to note that the $B S E$ is an instrument regulating electricity prices with the official objective of reducing energy poverty. Thus, there is a misalignment between the objective of the policy, the instrument used, and the targeted beneficiaries. Indeed, income poverty and energy poverty, though closely related, are distinct issues. By including income criteria in the targeting of the policy, the risk of including household decreases but the risk of excluding households in energy poverty increases. If the government aims to address directly energy poverty, it could either include this in its targeting strategy, or it could use another instrument. In the former case, eligibility criteria could for instance include the energy efficiency characteristics of the dwellings. In the latter case, there could be policies aiming directly at improving energy efficiency. However, to achieve a reduction of energy poverty, these policies should prioritize the most disadvantaged, which has been seldom the case in practice (Tirado Herrero and Jiménez Meneses, 2016).

Overall, we can conclude that, even if the magnitude of our main result is a lower bound, the $B S E$ shows signs of a failed policy. More transparency is needed on who bears its costs, and there should be a more explicit alignment on the objective of the policy, the instrument used, and its targeting policy.

\section{Conclusions}

This paper assesses the effectiveness of a policy instrument, an electricity social rate, introduced to increase the affordability of electricity for vulnerable consumers in Spain. The analysis reveals that this subsidy, which targets electricity prices, is effective in reducing the likelihood of energy poverty for eligible households. The magnitude of the effect is however quite modest.

The additional and powerful result derived from the analysis is that, given the reduction of the effective price of electricity for eligible households, these do not alter their quantities of electricity purchased but react entirely through a lower expenditure in electricity. In other words, this subsidy does not change the behavior of households in terms of consumption of electricity. Several interpretation could be given for this finding. First, an optimist reader could see this as a positive result. Indeed, one could think that if households do not increase their consumption of electricity even though its effective price has decreased, it is because electricity is a necessity good, which consumption was already entirely satisfied before the subsidy, or in other words that these households do not ration their electricity. In such a scenario, the newly available budget coming from a decrease in electricity expenditure could be entirely allocated to other expenditures and improve the household well-being. 
Another interpretation, less optimistic, would be that the vulnerable households targeted by the $B S E$ were rationing their electricity consumption before the introduction of the policy, and still ration their consumption after the policy. In such a scenario, vulnerable households have to ration on several necessity goods, and the newly released budget from lower electricity expenditure would be entirely spent in reducing the rationing of other goods, which can be energy-related, such as gas, or other essential goods or services. Of course, it could also be the case that some households are in the first scenario and others in the second. Our analysis does not allow, however, to identify between these two scenarios and future research should look at how households reallocate their expenditure after the subsidy of one particular good.

Our research is a first step in increasing the understanding of this particular subsidy reform, for which we knew quite little. We are able to provide a lower bound on the impact of this policy on the likelihood of energy poverty. Additional research should provide a more accurate estimate of the true effect, or at least a higher bound of the estimate. Moreover, there is still more to understand in the financing strategy of this policy. Indeed, as electricity companies finance the subsidy, there is an important need for transparency. The policy instrument was advertised as being entirely financed by the private electric companies, without involving any public funds. However, this seems unlikely. The policy could have had a fiscal cost, probably in terms of foregone fiscal revenues through lower VAT rates. Another possibility is that other consumers could have financed the policy through cross-subsidies. Further research should investigate in this direction with the objective of revealing, or identifying, the true financing source in order to provide a more comprehensive evaluation of the policy.

Another important debate stems from the targeting of the BSE. There exists a large literature on the incidence of subsidies delivered by utilities through tariff structures. Whittington et al. (2015) show for example that subsidies delivered through the most common tariff structure, i.e. that are based on consumption, are very poorly targeted to the poorest households. The authors recommend to focus instead on alternative subsidy targeting mechanisms such as means testing. The BSE does identify four socioeconomic criteria for its eligibility, but its introduction in 2009 was immediately criticized for its poor targeting power (e.g. Tirado Herrero and Jiménez Meneses (2016)). Indeed, by not including incomerelated characteristics in the criteria for eligible consumers, it was argued that vulnerable households could be left out and households that were not in energy poverty could become eligible. This is one of the main reasons for the change in the policy in 2018, which includes the income level of households as a criteria for the $B S E$ eligibility. ${ }^{16}$ The targeting performance of the $B S E$ is not the topic of the paper, but the conclusions should be conceived in this particular context. Future research should determine whether the conclusions hold

\footnotetext{
${ }^{16}$ https://www. boe.es/eli/es/rd/2017/10/06/897
} 
to the inclusion of income as a targeting criteria, in particular in terms of consumption behavior.

Nonetheless, including income criteria, though it better targets vulnerable households, does not solve the issue of misalignment between the objective of the policy, the instrument used and its targeted population. Indeed, it is a policy aiming at decreasing energy poverty with an instrument focusing on electricity prices while the whole targeting strategy is designed around income vulnerability. Further research should therefore analyze whether an alternative targeting strategy or an alternative instrument could be more effective ways of reducing energy poverty.

Finally, other significant policy changes occurred to the energy sector during the past 15 years in Spain. For instance, in 2013, the energy regulator changed from a single sector regulator to a multi-sector one. Other important changes concerned the use of renewable energies. More research should see how other policy and institutional reforms can affect energy poverty, an issue still salient today. 


\section{References}

Aristondo, O., and Onaindia, E. (2018). "Inequality of energy poverty between groups in Spain." Energy, 153, 431-442.

Awaworyi Churchill, S., Smyth, R., and Farrell, L. (2020). "Fuel poverty and subjective wellbeing." Energy Economics, 86, 104650.

Bagnoli, L., Bertomeu, S., Estache, A., Vagliasindi, M., et al. (2020). "Are the poor better off with public or private utilities? A survey of the academic evidence on developing economies." ECARES Working Paper No. 2020-24.

Balza, L., Jimenez, R., and Mercado, J. (2013). "Privatization, institutional reform, and performance in the Latin American electricity sector." Inter-American Development Bank, Infrastructure and Environment Department, Energy Division, Technical Note No. IDBTN-599.

Besagni, G., and Borgarello, M. (2018). "The determinants of residential energy expenditure in Italy." Energy, 165, 369-386.

Castaño-Rosa, R., Solís-Guzmán, J., Rubio-Bellido, C., and Marrero, M. (2019). "Towards a multiple-indicator approach to energy poverty in the European Union: A review." Energy and Buildings, 193, 36-48.

Costa-Campi, M. T., José-Llopis, E., and Trujillo-Baute, E. (2019). "La pobreza energética en España. aproximación desde una perspectiva de ingresos." Instituto de Economía de Barcelona, Cátedra de sostenibilidad energética.

Deller, D. (2018). "Energy affordability in the EU: The risks of metric driven policies." Energy Policy, 119, 168-182.

García Alvarez, G., and Tol, R. (2020). "The impact of the Bono Social de Electricidad on energy poverty in Spain." Department of Economics, University of Sussex Business School.

Haas, T. (2019). "Comparing energy transitions in Germany and Spain using a political economy perspective." Environmental Innovation and Societal Transitions, 31, 200-210.

Healy, J. D., and Clinch, J. P. (2002). "Fuel poverty in Europe: A cross country analysis using a new composite measurement." Environmental studies research series working papers.

Heindl, P., and Schüssler, R. (2015). "Dynamic properties of energy affordability measures." Energy Policy, 86, 123-132. 
Hills, J. (2012). "Getting the measure of fuel poverty: Final report of the fuel poverty review." CASEreport, 72. Centre for Analysis of Social Exclusion, London School of Economics and Political Science, London, UK.

Jimenez, R., and Yepez-Garcia, A. (2017). "Understanding the drivers of household energy spending: Micro evidence for Latin America.” IDB Working Paper Series.

Lasarte Navamuel, E., Rubiera Morollón, F., and Moreno Cuartas, B. (2018). "Energy consumption and urban sprawl: Evidence for the Spanish case." Journal of Cleaner production, 172, 3479-3486.

Legendre, B., and Ricci, O. (2015). "Measuring fuel poverty in France: Which households are the most fuel vulnerable?" Energy Economics, 49, 620-628.

Miniaci, R., Scarpa, C., and Valbonesi, P. (2014). "Energy affordability and the benefits system in Italy." Energy Policy, 75, 289-300.

Ministerio para la Transición Ecológica (2019). "Estrategia Nacional contra la pobreza energética 2019-2024."

Mohr, T. M. (2018). "Fuel poverty in the US: evidence using the 2009 Residential Energy Consumption Survey." Energy Economics, 74, 360-369.

Okushima, S. (2017). "Gauging energy poverty: A multidimensional approach." Energy, 137, 1159-1166.

Phimister, E., Vera-Toscano, E., and Roberts, D. (2015). "The dynamics of energy poverty: evidence from Spain." Economics of Energy \& Environmental Policy, 4(1), 153-166.

Poggi, A., and Florio, M. (2010). "Energy deprivation dynamics and regulatory reforms in Europe: Evidence from household panel data." Energy Policy, 38(1), 253-264.

Pye, S., Baffert, C., Brajković, J., Grgurev, I., De Miglio, R., and Deane, P. (2015). "Energy poverty and vulnerable consumers in the energy sector across the EU: analysis of policies and measures." INSIGHT_E Policy Report.

Rademaekers, K., Yearwood, J., Ferreira, A., Pye, S., Hamilton, I., Agnolucci, P., Grover, D., Karásek, J., and Anisimova, N. (2016). "Selecting indicators to measure energy poverty." Trinomics. Under the Pilot Project "Energy Poverty - Assessment of the Impact of the Crisis and Review of Existing and Possible New Measures in the Member States. Framework Contract ENER/A4/516-2014.

Robinson, C., Bouzarovski, S., and Lindley, S. (2018). "'Getting the measure of fuel poverty': The geography of fuel poverty indicators in England." Energy Research 83 Social Science, 36, 79-93. 
Scarpellini, S., Rivera-Torres, P., Suárez-Perales, I., and Aranda-Usón, A. (2015). "Analysis of energy poverty intensity from the perspective of the regional administration: Empirical evidence from households in southern Europe." Energy Policy, 86, 729-738.

Thomson, H., Snell, C. J., and Liddell, C. (2016). "Fuel poverty in the European Union: a concept in need of definition?" People, Place 85 Policy Online, 5-24.

Tirado Herrero, S., and Jiménez Meneses, L. (2016). "Energy poverty, crisis and austerity in Spain." People, Place and Policy, 10(1), 42-56.

Tirado Herrero, S., Jiménez Meneses, L., López Fernández, J. L., and Irigoyen Hidalgo, V. M. (2018). "Pobreza energética en España. hacia un sistema de indicadores y una estrategia de actuación estatales." Asociación de Ciencias Ambientales, Madrid.

Tirado Herrero, S., Jiménez Meneses, L., López Fernández, J. L., and Martín García, J. (2014). "Pobreza energética en España. análisis de tendencias." Asociación de Ciencias Ambientales, Madrid.

Whittington, D., Nauges, C., Fuente, D., and Wu, X. (2015). "A diagnostic tool for estimating the incidence of subsidies delivered by water utilities in low-and medium-income countries, with illustrative simulations." Utilities Policy, 34, 70-81. 


\section{Appendices}

\section{A Data cleaning process}

This sections details the steps of data cleaning process in the analysis. We start with 261,478 observations. Among these households, we first remove those who have a zero value in either the expenditure in electricity or in the quantity of electricity consumed by the household. ${ }^{17}$ In a second step, to reduce the presence of outliers, we trimmed the sample by removing the bottom $1 \%$ and top $1 \%$ of the distribution of share of expenditure in electricity (see Jimenez and Yepez-Garcia (2017)). At this stage we have 249,422 observations.

Finally, our last manipulation concerns the prices of electricity. In the data, we do not directly observe the average effective price of electricity but we compute it by dividing expenditure by quantities. When we look at the distribution of these computed prices, we see that there are extremely high values (up to $343 € / \mathrm{kWh}$ as can be seen in Table A.1). ${ }^{18}$ To address this issue, we trim the sample by removing the top $1 \%$ of the distribution of effective electricity prices. The comparison of distributions before and after this trimming is presented in Figure A.1. This leads to our final sample, which includes 246,928 observations.

\begin{tabular}{l|ccccc}
\hline Effective price of electricity & Obs. & Mean & St. Dev. & Min. & Max. \\
\hline Before cleaning & 249,422 & 0.230 & 1.316 & 0.008 & 343.29 \\
After cleaning & 246,928 & 0.214 & 0.055 & 0.008 & 0.475 \\
\hline
\end{tabular}

Average over 2006-2017. Effective prices are indexed using IPC base 2016.

Table A.1: Summary statistics - Effective electricity prices: before and after cleaning

\footnotetext{
${ }^{17}$ Note that the expenditure in electricity account for both monetary and non monetary expenditure. The non-monetary expenditure includes for instance self-consumption or in-kind salaries. Households with non monetary expenditure are a very small share of the whole sample $(0.3 \%)$ but we exclude from the analysis only households with a null total expenditure in electricity, including both monetary and non-monetary expenditure.

${ }^{18}$ Note that when we talk about effective electricity prices before cleaning, we still account for the two cleaning processes explained in the previous paragraph.
} 

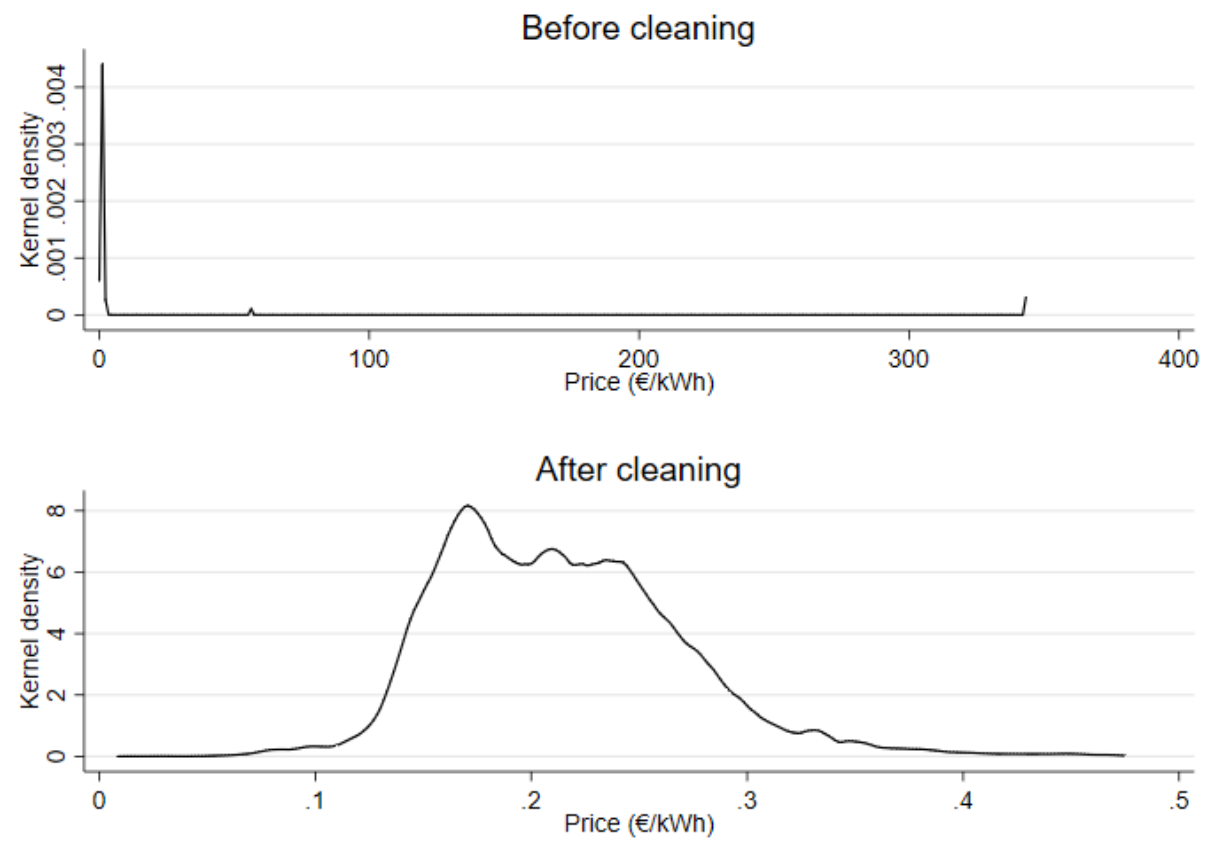

Source: EPF 2006-2017

Figure A.1: Kernel density of effective electricity prices: before and after cleaning

\section{B Eligibility to BSE: Identification of the criteria of mini- mum pension}

As the data does not allow to exactly identify whether the household consist of retirees receiving the minimum pension, we rely on the following strategy to proxy for this criteria.

The Spanish Ministry of Labour and Social Economy has published the yearly minimum pensions. ${ }^{19}$ The level of the minimum pension depend on two criteria:

- Whether the retiree receiving the pension is (a) with a dependent spouse (b) with a non-dependent spouse (c) with no spouse (i.e. a single economic unit)

- Whether the retiree is over 65 years old or between 60 and 64 years old.

We therefore construct four categories of households among households whose main source of income is pension.

Category A Households with only 1 member, age over 65 years old. Their minimum pension is that of single economic unit, for the age of over 65 years old.

Category B Households with only 1 member, age between 60 and 65 years old. Their

\footnotetext{
${ }^{19}$ http://www.mites.gob.es/es/estadisticas/index.htm
} 
minimum pension is that of single economic unit, for the age of between 60 and 64 years old.

Category C Households with more than 1 member, only 1 member earns an income. When there are more than 1 member, we are not able to identify the age of the person receiving the pension. We assume that the member receiving the income is over 65 years old. Therefore, we consider that their minimum pension is that of a retiree over 65 years old with a dependent spouse.

Category D Households with more than 1 member and with more than 1 member earns an income. As for category $\mathrm{C}$, we assume that members are over 65 years old. We consider that their minimum pension is that of two retirees over 65 years old receiving both a pension for persons with non dependent spouse.

Table B.1 presents the official minimum pension for each of the four categories. We therefore consider that a households is eligible for the minimum pension criteria if its main source of income is from pension and if its annual income is smaller or equal to the minimum threshold of its category and its year. Note that for Category D, since we consider two retirees, the condition is that the annual income must be smaller or equal to twice the minimum threshold of its category and its year.

\begin{tabular}{c|c|c|c|c}
\hline Year & Category A & Category B & Category C & Category D \\
\hline 2006 & $6,576.22$ & $6,127.52$ & $7,966.98$ & $6,347.63$ \\
2007 & $7,047.32$ & $6,566.56$ & $8,659.56$ & $6,834.28$ \\
2008 & $7,428.82$ & $6,922.16$ & $9,258.76$ & $7,238.42$ \\
2009 & $7,861.70$ & $7,339.92$ & $9,746.66$ & $7,651.70$ \\
2010 & $8,335.60$ & $7,796.60$ & $10,284.40$ & $7,905.80$ \\
2011 & $8,577.80$ & $8,023.40$ & $10,584.00$ & $8,135.40$ \\
2012 & $8,664.60$ & $8,104.60$ & $10,690.40$ & $8,218.00$ \\
2013 & $8,838.20$ & $8,267.00$ & $10,904.60$ & $8,383.20$ \\
2014 & $8,860.60$ & $8,288.00$ & $10,932.60$ & $8,404.20$ \\
2015 & $8,883.00$ & $8,309.00$ & $10,960.60$ & $8,426.60$ \\
2016 & $8,905.40$ & $8,330.00$ & $10,988.60$ & $8,449.00$ \\
2017 & $8,927.80$ & $8,351.00$ & $11,016.60$ & $8,471.40$ \\
\hline
\end{tabular}

Source: Ministry of Labour and Social Economy

Note: The values were not available for Category D between 2006 and 2008. For each of these three years, we predicted them using the average growth rate of the other three categories between that year and 2009 .

Table B.1: Official minimum pension for the different categories (in $€$ per year)

Table B.2 presents some descriptive statistics about the share of households who receive the minimum pension. Among all households who receive their main income from pensions, $31.3 \%$ of them receive an amount lower or equal to the minimum pension as defined by Table B.1. This varies a little over the four categories. For instance, $24 \%$ of single member 
households younger than 65 years old (Category B) receive the minimum pension, while this share jumps to $35 \%$ for households in which one person receives a pension and has a dependent spouse (Category C).

\begin{tabular}{l|ccc}
\hline Category & Obs. & Mean & Std. Dev. \\
\hline Category A & 17,974 & 0.343 & 0.475 \\
Category B & 3,452 & 0.243 & 0.429 \\
Category C & 23,794 & 0.350 & 0.477 \\
Category D & 36,025 & 0.281 & 0.449 \\
\hline Total & 81,245 & 0.313 & 0.464 \\
\hline
\end{tabular}

Note: The total corresponds to all households whose main source of income is pension.

Table B.2: Share of households with the minimum pension

\section{Descriptive statistics: Hidden energy poverty}

\begin{tabular}{cccc}
\hline \multicolumn{4}{c}{ Summary statistics } \\
\hline Hidden Energy Poverty (HEP) & 246,928 & Mean & St. Dev. \\
\hline \multicolumn{4}{c}{ Correlation with BSE elgibility } \\
\hline \\
Hidden Energy Poverty (HEP) & 246,928 & Correlation & p-value \\
\hline
\end{tabular}

Average over 2006-2017. Hidden Energy Poverty $=1$ if expenditure in electricity is above $0.5^{*}$ national median that year. Expenditures are indexed on IPC (base 2016). N: number of observations. St. Dev.: standard deviation.

Table C.1: Descriptive statistics: Hidden energy poverty 
D Sensitivity analysis to the energy poverty threshold

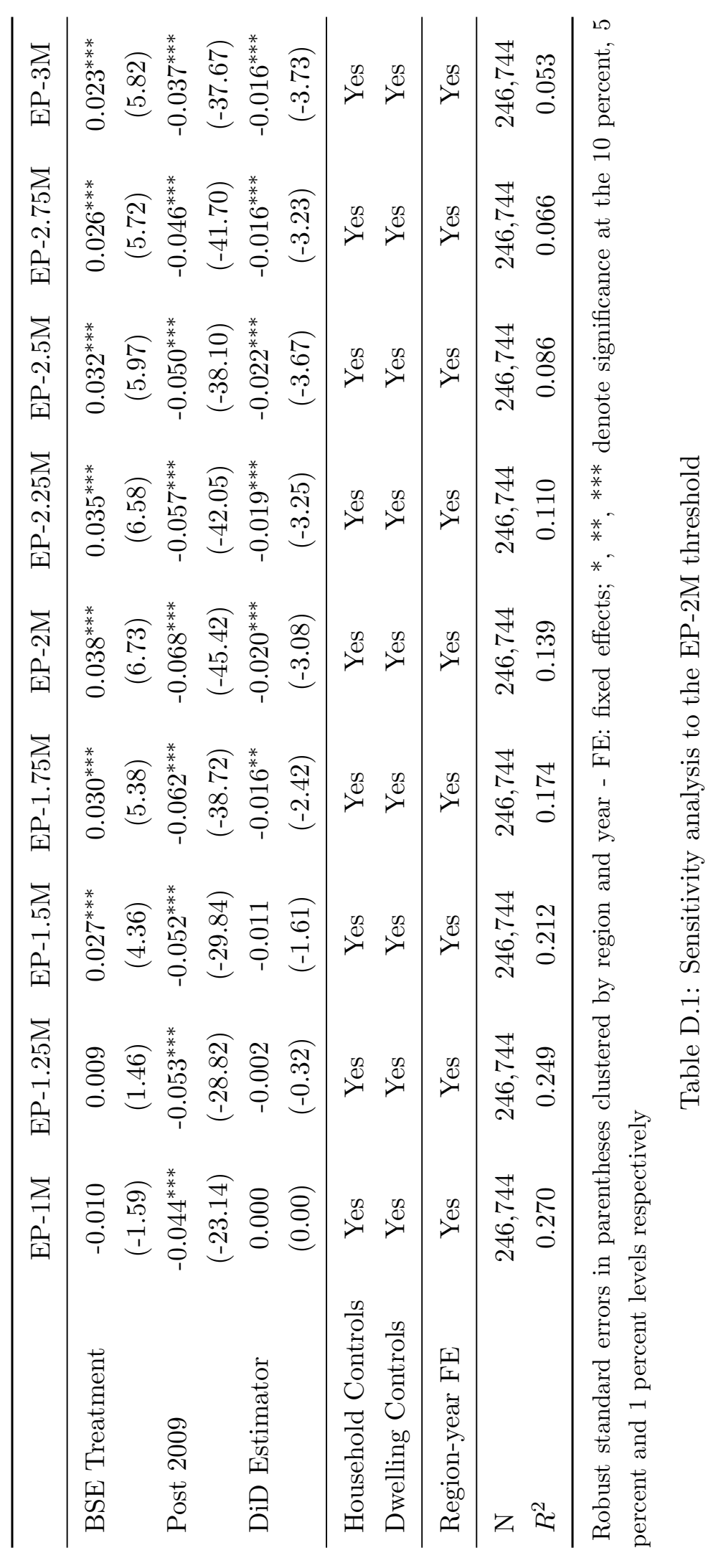

